
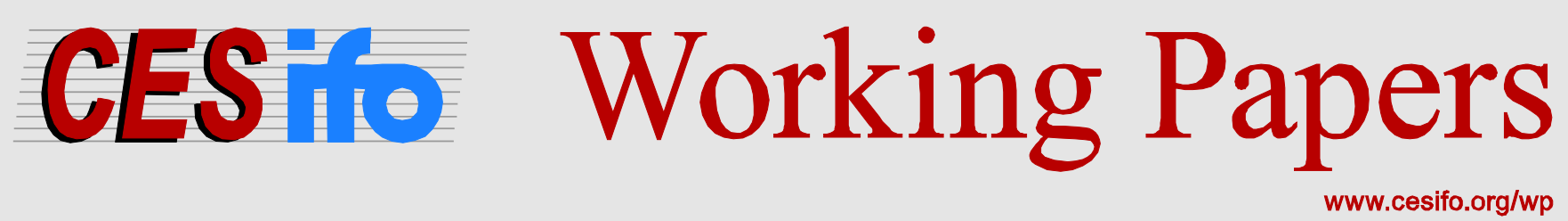

\title{
The Impact of Trade Liberalization on Industrial Productivity
}

\author{
Paul S. Segerstrom \\ Yoichi Sugita
}
CESIFO WORKING PAPER NO. 4365
CATEgory 8: TRAde Policy
August 2013
An electronic version of the paper may be downloaded
- from the SSRN website:
- from the RePEc website:
- from the CESifo website:
wWw.SSRN.com
www.RePEc.org
www.CESifo-group.org/wp

\section{CESifo}




\title{
The Impact of Trade Liberalization on Industrial Productivity
}

\begin{abstract}
This paper calls into question the currently most influential model of international trade. An empirical finding by Trefler (2004, AER) and others that industrial productivity increases more strongly in liberalized industries than in non-liberalized industries has been widely accepted as evidence for the Melitz (2003, Econometrica) model. We show that a multiindustry version of the Melitz model does not predict this relationship. Instead, it predicts the opposite relationship that industrial productivity increases more strongly in non-liberalized industries than in liberalized industries.
\end{abstract}

JEL-Code: F120, F130.

Keywords: trade liberalization, firm heterogeneity, industrial productivity.

Paul S. Segerstrom Stockholm School of Economics Department of Economics Box 6501 Sweden - 11383 Stockholm paul.segerstrom@hhs.se
Yoichi Sugita

Stockholm School of Economics

Department of Economics

Box 6501

Sweden - 11383 Stockholm

yoichi.sugita@hhs.se

First version: June 22, 2012

Current version: June 28, 2013

We thank Don Davis, Tore Ellingsen, Erik Lindqvist, John Morrow, Alexander Tarasov and seminar participants at the Stockholm School of Economics, the Midwest International Trade Meeting, Erasmus University Rotterdam, HEC Paris, the Hitotsubashi GCOE Conference on Trade and FDI 2012, Uppsala University, Research Institute of Industrial Economics, and the CESifo-Delphi conference 2013 in Munich for helpful comments. Financial support from theWallander Foundation is gratefully acknowledged. 


\section{Introduction}

A central question in the study of international trade is how trade liberalization improves resource allocation in the liberalizing country. While traditional studies have emphasized reallocation across industries, recent studies have discovered that reallocation occurs even within industries. In the last decade, the empirical literature has established that trade liberalization improves productivity by shifting resources from less productive to more productive firms within industries.

By comparing industries that experienced different degrees of trade liberalization (e.g. tariff cuts), several studies found that intra-industry reallocation improves industrial productivity more strongly in liberalized industries than in non-liberalized industries. ${ }^{1}$ For instance, by investigating the long run impact of the Canada-USA free trade agreement on Canadian manufacturing industries, Trefler (2004) found that industrial productivity increased more strongly in liberalized industries than in nonliberalized industries, and that the rise in industrial productivity was mainly due to the shift of resources from less productive to more productive firms. Lileeva (2008, for Canada) and Eslava, Haltiwanger, Kugler and Kugler (2013, for Colombia) also found that the exit of low productivity firms from an industry, which contributes to a rise in industrial productivity, is positively associated with the decrease in tariffs in the industry. By estimating the quantile regression of productivity for India's manufacturing firms on tariff cuts in the large trade reform of 1991, Nataraji (2011) found that firm productivity at lower percentiles increased more strongly in liberalized industries than in non-liberalized industries, which suggests that the least productive firms were exiting from liberalized industries. ${ }^{2}$

The seminal model by Melitz (2003) has been accepted as the central model of intra-industry reallocation due to trade liberalization. By combining the Hopenhayn (1992) model of the entry and exit of heterogeneous firms and the Krugman $(1979,1980)$ model with fixed trade costs, Melitz (2003) theoretically demonstrated that trade liberalization improves the aggregate productivity of economies through resource reallocation toward more productive firms. The reallocation mechanism of Melitz (2003) has been applied to various issues and is central to the theoretical trade research of the last

\footnotetext{
${ }^{1}$ Early studies use firm size as a proxy for firm productivity (e.g. Head and Ries, 1999; Baggs, 2005) and/or trade volume as a proxy for trade policy measures (e.g. Pavcnik, 2002). Recent studies use more direct productivity measures and trade policy measures. Tybout (2003) surveys early studies in this literature.

${ }^{2}$ Other studies found positive but statistically insignificant associations between productivity improvement due to intraindustry reallocation and the extent of liberalization (e.g. Tybout and Westbrook, 1995, for Mexico; Fernandes, 2007, for Colombia; Sivadasan, 2009, and Harrison, Martin, and Nataraj, 2013, for India). We are not aware of any study reporting the opposite negative association with statistical and economic significance.
} 
decade.

It is widely believed that the Melitz model explains the fact that industrial productivity increases more strongly in liberalized industries than in non-liberalized industries. Virtually all survey papers recently written by leading scholars cite Trefler (2004) as evidence in support of the Melitz model (Bernard, Jensen, Redding, and Schott, 2007, 2012; Helpman, 2011; Redding, 2011; Melitz and Trefler, 2012; Melitz and Redding, 2012). For instance, Helpman (2011, p.107) writes in his recent book: "In other words, the Canadian experience conforms to the theoretical analysis." Empirical researchers compare their findings and the Melitz model based on the same belief (e.g. Eslava et al., 2013; Fernandes, 2007; Harrison et al., 2013; Nataraj, 2011; Sivadasan, 2009).

The purpose of our paper is to revisit the correspondence between empirical studies and the Melitz model. The type of trade liberalization that typical empirical studies investigated is different from the type of trade liberalization that Melitz (2003) theoretically analyzed. The liberalization in the one industry Melitz model is multilateral and uniform liberalization, in which all countries reduce tariffs on all goods by the same amount. On the other hand, the above mentioned empirical studies investigate unilateral and non-uniform liberalization, in which one country reduces tariffs and the extent of tariff reductions vary across industries. ${ }^{3}$

The gap between theory and evidence has probably been overlooked because the analysis of unilateral and non-uniform trade liberalization in a multi-industry Melitz model appears to be complicated and intractable. To overcome this theoretical difficulty, we develop a brand new way of solving the Melitz model using simple and intuitive diagrams. We show that these new techniques can be used to solve a multi-industry version of the Melitz model (the original model has just one industry) and study what happens when one country reduces tariffs in some industries but not others (unilateral and non-uniform trade liberalization).

Our surprising result is that the multi-industry Melitz model does not predict that industrial productivity rises more strongly in liberalized industries than in non-liberalized industries. Instead, it predicts the opposite relationship that industrial productivity rises more strongly in non-liberalized industries than in liberalized industries. This result forces us to re-think the match between theory and evidence:

\footnotetext{
${ }^{3}$ Trefler (2004) and Lileeva (2008) controlled for the US tariff changes when they estimate the impact of the Canadian tariff cuts introduced by the Canada-USA free trade agreement (CUFTA). Therefore, although the CUFTA is a bilateral trade agreement, the effects of Canadian tariff cuts estimated by these two papers should be interpreted as the effects of unilateral trade liberalization.
} 
an empirical fact that has been widely cited as evidence for the Melitz model is actually evidence against the Melitz model. Furthermore, when the size of a liberalized industry is small compared to the size of the liberalizing country, we find a more striking prediction: industrial productivity decreases in the liberalized industry, while it increases in the non-liberalized industries. This result calls for rethinking the model's implications for industrial promotion policy. If the government of a country is interested in raising the productivity of a small "target" industry through a resource reallocation from less productive to more productive firms, the theoretically correct advice based on the Melitz model is to protect the target industry, not trade liberalization. This is obviously the opposite of what Trefler (2004) and other empirical studies suggest.

As illustrated in Table 1, no previous paper has analyzed unilateral and non-uniform trade liberalization in a Melitz model with multiple Melitz industries. This is required to compare the model with the empirical facts from cross-industry regressions. Demidova and Rodriguez-Clare $(2009,2013)$ and Felbermayr, Jung, and Larch (2013) analyze unilateral trade liberalization in models with just one Melitz industry. ${ }^{4}$ Bernard, Redding, and Schott (2007) and Okubo (2009) develop models with multiple Melitz industries but only analyze multilateral trade liberalization.

\begin{tabular}{|c|c|c|}
\hline & One Melitz Industry & Multiple Melitz Industries \\
\hline $\begin{array}{c}\text { Multilateral } \\
\text { Liberalization }\end{array}$ & Melitz (03) & $\begin{array}{c}\text { Bernard, Redding \& Schott (07) } \\
\text { Okubo (09) }\end{array}$ \\
\hline $\begin{array}{c}\text { Unilateral } \\
\text { Liberalization }\end{array}$ & $\begin{array}{c}\text { Demidova \& Rodriguez-Clare }(09,13) \\
\text { Felbermayr, Jung \& Larch }(13)\end{array}$ & Our paper \\
\hline
\end{tabular}

Table 1: Previous studies on trade liberalization using versions of the Melitz model

Demidova and Rodriguez-Clare (2013) is the most closely related paper to our work. They also analyze unilateral liberalization in the Melitz (2003) model by using simple diagrams. However, they analyze a different type of unilateral liberalization and reach different conclusions. Demidova and Rodriguez-Clare (2013) analyze a model with only one industry and find that productivity increases in the liberalized industry. ${ }^{5}$ In contrast, our paper analyzes non-uniform liberalization in a model with

\footnotetext{
${ }^{4}$ Melitz and Ottaviano (2008) analyze unilateral liberalization in a model of heterogeneous firms where heterogeneous firms exist only in one industry. The model differs considerably from Melitz (2003) because it has variable markups and there is a homogeneous good that is freely traded across countries.

${ }^{5}$ Strictly speaking, Demidova and Rodriguez-Clare (2013) demonstrate that unilateral liberalization increases the welfare of the liberalizing country. Our Lemma 3 below shows that in their one industry setting, an increase in welfare is equivalent to an increase in industrial productivity.
} 
multiple industries, which nests Domediova and Rodriguez-Clare (2013)'s analysis of uniform liberalization as a special case. Our main finding is that productivity increases more in the non-liberalized industries than in the liberalized industries. This finding requires the comparison of liberalized industries and non-liberalized industries, which is not possible in their single industry model. Furthermore, we show that their finding that productivity increases in the liberalized industry depends on the single industry setting. If the liberalized industry is sufficiently small compared to the rest of the economy, we find that productivity decreases in the liberalized industry.

The rest of the paper is organized as follows. In section 2, we present a multi-industry version of the Melitz (2003) model. In section 3, we solve the model analytically for the effects of trade liberalization and explain the intuition behind the results. In section 4, we calibrate the Melitz model to match US-Canada trade and then show that there is a big difference between the implications of trade liberalization in the calibrated Melitz model and what Trefler (2004) found empirically. In section 5, we offer some concluding comments and there is an Online Appendix where calculations that we did to solve the model are presented in more detail.

\section{The Model}

This section presents a multi-industry version of the Melitz (2003) model. Our model differs from the original model in five points: (1) our model has two industries and two countries; (2) industries and countries are asymmetric so that wages differ between countries; (3) trade costs are asymmetric and depend on the direction of trade; (4) the utility function of consumers has two tiers, the Cobb-Douglas upper tier and the CES lower tier; and (5) firms draw their productivities from Pareto distributions. The last two specifications are commonly used in applications of the Melitz model.

\subsection{Setting}

Consider two countries, 1 and 2, with two differentiated goods sectors (or industries), $A$ and $B$. Throughout the paper, subscripts $i$ and $j$ denote countries $(i, j \in\{1,2\})$ and subscript $s$ denotes sectors $(s \in\{A, B\})$. Though the model has infinitely many periods, there is no means for saving over periods. Following Melitz (2003) and most theoretical applications of the Melitz model, we focus on a stationary steady state equilibrium where aggregate variables do not change over time and omit 
notation for time periods.

The representative consumers in both countries have an identical two-tier (Cobb-Douglas plus CES) utility function:

$$
U \equiv C_{A}^{\alpha_{A}} C_{B}^{\alpha_{B}} \quad \text { where } \quad C_{s} \equiv\left[\int_{\omega \in \Omega_{s}} q_{s}(\omega)^{\rho_{s}} d \omega\right]^{1 / \rho_{s}}
$$

In equation (1), $q_{s}(\omega)$ is the consumer's quantity consumed of a product variety $\omega$ produced in sector $s, \Omega_{s}$ is the set of available varieties in sector $s$ and $\rho_{s}$ measures the degree of product differentiation in sector $s$. We assume that products within a sector are closer substitutes than products across sectors, which implies that a within-sector elasticity of substitution $\sigma_{s} \equiv 1 /\left(1-\rho_{s}\right)$ satisfies $\sigma_{s}>1$. Given that $\alpha_{A}+\alpha_{B}=1, \alpha_{s}$ represents the share of consumer expenditure on sector $s$ products.

Country $i$ is endowed with $L_{i}$ unit of labor as the only factor of production. Labor is inelastically supplied and workers in country $i$ earn the competitive wage rate $w_{i}$. We measure all prices relative to the price of labor in country 2 by setting $w_{2}=1$.

Firms are risk neutral and maximize expected profits. In each time period, let $M_{i s e}$ denote the measure of firms that choose to enter in country $i$ and sector $s$. Each firm uses $F_{i s}$ units of labor to enter and incurs the fixed entry cost $w_{i} F_{i s}$. Each firm then independently draws its productivity $\varphi$ from a Pareto distribution. The cumulative distribution function $G_{i s}(\varphi)$ and the density function $g_{i s}(\varphi)$ are given by

$$
G_{i s}(\varphi)=1-\left(\frac{b_{i s}}{\varphi}\right)^{\theta_{s}} \text { and } g_{i s}(\varphi)=\frac{\theta_{s} b_{i s}^{\theta_{s}}}{\varphi^{\theta_{s}+1}} \text { for } \varphi \in\left[b_{i s}, \infty\right)
$$

where $\theta_{s}$ and $b_{i s}$ are the shape and scale parameters of the distribution for country $i$ and sector $s$. We assume that $\theta_{s}>\sigma_{s}-1$ to guarantee that expected profits are finite. A firm with productivity $\varphi$ uses $1 / \varphi$ units of labor to produce one unit of output and has constant marginal cost $w_{i} / \varphi$ in country $i$. This firm must use $f_{i j s}$ units of labor and incur the fixed "marketing" cost $w_{i} f_{i j s}$ to sell in country $j$. There are also iceberg trade costs associated with shipping products across countries: a firm that exports from country $i$ to country $j \neq i$ in sector $s$ needs to ship $\tau_{i j s}>1$ units of a product in order for one unit to arrive at the foreign destination (if $j=i$, then $\tau_{i i s}=1$ ).

Because of the fixed marketing costs, there exist productivity cut-off levels $\varphi_{i j s}^{*}$ such that only firms with $\varphi \geq \varphi_{i j s}^{*}$ sell products from country $i$ to country $j$ in sector $s$. In each country and sector, 
we assume that exporting require higher fixed costs than local selling $\left(f_{i j s}>f_{i i s}\right)$. We solve the model for an equilibrium where both countries produces both goods $A$ and $B$, and the more productive firms export $\left(\varphi_{i i s}^{*}<\varphi_{i j s}^{*}\right)$. In each period, there is an exogenous probability $\delta_{i s}$ with which actively operating firms in country $i$ and sector $s$ die and exit. In a stationary steady state equilibrium, the mass of actively operating firms $M_{i s}$ and the mass of entrants $M_{i s e}$ in country $i$ and sector $s$ satisfy

$$
\left[1-G_{i s}\left(\varphi_{i i s}^{*}\right)\right] M_{i s e}=\delta_{i s} M_{i s}
$$

that is, firm entry in each time period is matched by firm exit.

Let $p_{i j s}(\varphi)$ denote the price charged in country $j$ by a firm with productivity $\varphi$ from country $i$ in sector $s$. Let $q_{i j s}(\varphi)$ denote the quantity that consumers in country $j$ buy from this firm and let $r_{i j s}(\varphi) \equiv p_{i j s}(\varphi) q_{i j s}(\varphi)$ denote the corresponding firm revenue. Also, let $P_{j s}$ denote the index of consumer prices in country $j$ and sector $s$. Since free entry implies that aggregate profit income is zero, in each time period, consumers in country $j$ spend exactly what they earn in wage income $w_{j} L_{j}$. Consumer optimization calculations imply that consumer demand and the corresponding firm revenue are

$$
q_{i j s}(\varphi)=\frac{p_{i j s}(\varphi)^{-\sigma_{s}} \alpha_{s} w_{j} L_{j}}{P_{j s}^{1-\sigma_{s}}} \text { and } r_{i j s}(\varphi)=\frac{p_{i j s}(\varphi)^{1-\sigma_{s}} \alpha_{s} w_{j} L_{j}}{P_{j s}^{1-\sigma_{s}}}
$$

A firm with productivity $\varphi$ from country $i$ earns variable profit $\pi_{i j s}(\varphi)=r_{i j s}(\varphi)-\frac{w_{i} \tau_{i j s}}{\varphi} q_{i j s}(\varphi)$ from selling to country $j$ in sector $s$. Solving for the profit-maximizing price, we obtain that

$$
p_{i j s}(\varphi)=\frac{w_{i} \tau_{i j s}}{\rho_{s} \varphi}
$$

that is, each firm charges a fixed markup over its marginal cost $w_{i} \tau_{i j s} / \varphi$. Substituting this price back into the variable profit function yields $\pi_{i j s}(\varphi)=r_{i j s}(\varphi) / \sigma_{s}$.

\subsection{Sector Equilibrium}

We first derive equilibrium conditions for each sector, following the steps in Melitz (2003) and other previous studies. Since a firm with cut-off productivity $\varphi_{i j s}^{*}$ just breaks even from selling to country $j$, 
it follows that $\varphi_{i j s}^{*}$ is determined by the cut-off productivity condition

$$
\frac{r_{i j s}\left(\varphi_{i j s}^{*}\right)}{\sigma_{s}}=w_{i} f_{i j s}
$$

A firm from country $i$ needs to have productivity $\varphi \geq \varphi_{i j s}^{*}$ to justify paying the fixed marketing cost $w_{i} f_{i j s}$ of serving the country $j$ market in sector $s$.

From (4), (5) and (6), the cut-off productivity levels of domestic and foreign firms in country $j$ are related by trade costs and labor costs as follows:

$$
\varphi_{i j s}^{*}=T_{i j s}\left(\frac{w_{i}}{w_{j}}\right)^{1 / \rho_{s}} \varphi_{j j s}^{*}
$$

where $T_{i j s} \equiv \tau_{i j s}\left(f_{i j s} / f_{j j s}\right)^{1 /\left(\sigma_{s}-1\right)}$ captures both variable and fixed trade costs from country $i$ to country $j$ relative to the fixed trade cost within country $j$.

Let $\mu_{i s}(\varphi)$ denote the equilibrium productivity density function for country $i$ and sector $s$. Since only firms with productivity $\varphi \geq \varphi_{i i s}^{*}$ produce in equilibrium and firm exit is uncorrelated with productivity, the equilibrium productivity density function is given by

$$
\mu_{i s}(\varphi) \equiv \begin{cases}\frac{g_{i s}(\varphi)}{1-G_{i s}\left(\varphi_{i i s}^{*}\right)} & \text { if } \varphi \geq \varphi_{i i s}^{*} \\ 0 & \text { otherwise }\end{cases}
$$

Given (3) and (8), the price index $P_{j s}$ satisfies

$$
P_{j s}^{1-\sigma_{s}}=\sum_{k=1,2} \frac{M_{k s e}}{\delta_{k s}} \int_{\varphi_{k j s}^{*}}^{\infty} p_{k j s}(\varphi)^{1-\sigma_{s}} d G_{k s}(\varphi)
$$

In each time period, there is free entry by firms in each sector $s$ and country $i$. Let $\bar{\pi}_{i s}$ denote the average profits across all domestic firms in country $i$ and sector $s$ (including the fixed marketing costs). Let $\bar{v}_{i s} \equiv \sum_{t=0}^{\infty}\left(1-\delta_{i s}\right)^{t} \bar{\pi}_{i s}=\bar{\pi}_{i s} / \delta_{i s}$ denote the present value of average profit flows in country $i$ and sector $s$, taking into account the rate $\delta_{i s}$ at which firms exit in each time period. Free entry implies that the probability of successful entry times the expected profits earned from successful entry must equal the cost of entry, that is, $\left[1-G_{i s}\left(\varphi_{i i s}^{*}\right)\right] \bar{\pi}_{i s} / \delta_{i s}=w_{i} F_{i s}$. Calculating the average profits across 
all domestic firms (exporters and non-exporters), we obtain

$$
\frac{1}{\delta_{i s}} \sum_{j=1,2} \int_{\varphi_{i j s}^{*}}^{\infty}\left[\frac{r_{i j s}(\varphi)}{\sigma_{s}}-w_{i} f_{i j s}\right] d G_{i s}(\varphi)=w_{i} F_{i s}
$$

that is, the expected lifetime profit from entry must be equal to the entry costs. Following Melitz (2003) and Demidova (2008), equation (10) can be rewritten as an expression of the cut-off productivity levels using (2), (5), and (6). Doing so yields the free entry condition

$$
\sum_{j=1,2} \gamma_{i s} f_{i j s} \varphi_{i j s}^{*-\theta_{s}}=F_{i s}
$$

where $\gamma_{1 s} \equiv b_{1 s}^{\theta_{s}}\left(\sigma_{s}-1\right) /\left[\delta_{1 s}\left(\theta_{s}-\sigma_{s}+1\right)\right]$.

For each sector $s$, four equations [(7) for $i j=12,21$ and (11) for $i=1,2]$ determine four cutoff productivity levels $\left[\varphi_{i j s}^{*}\right.$ for $\left.i j=11,12,21,22\right]$ as functions of $w_{1}$ and trade costs $\left(\tau_{12 s}, \tau_{21 s}\right)$. This simple observation highlights a general equilibrium effect of trade liberalization on industrial productivities: liberalization in one sector affects the cut-off productivity levels in other sectors through the factor market.

\subsection{General Equilibrium}

To analyze the general equilibrium effect linking the two sectors, we solve for the country 1 equilibrium wage rate $w_{1}$ directly from the country 1 labor market clearing condition. We are able to do so thanks to two convenient properties of the current model with the Cobb-Douglas upper tier utility (1) and the Pareto distribution (2).

The first convenient property is that labor demand $L_{i s}$ by all firms in country $i$ and sector $s$ is proportional to the mass of entrants $M_{i s e}$. We show this in three steps. First, equation (11) implies that the fixed costs (the entry costs plus the marketing costs) are proportional to the mass of entrants in each country $i$ and sector $s$ :

$$
w_{i}\left(M_{i s e} F_{i s}+\sum_{j=1,2} \int_{\varphi_{i j s}^{*}}^{\infty} f_{i j s} M_{i s} \mu_{i s}(\varphi) d \varphi\right)=w_{i} M_{i s e}\left(\frac{\theta_{s} F_{i s}}{\sigma_{s}-1}\right)
$$


Second, equation (10) implies that the fixed costs are equal to the gross profits in each country $i$ and sector $s$, that is, $w_{i} M_{i s e}\left(\frac{\theta_{s} F_{i s}}{\sigma_{s}-1}\right)=\sigma_{s}^{-1} \sum_{j=1,2} R_{i j s}$ where $R_{i j s} \equiv \int_{\varphi_{i j s}^{*}}^{\infty} r_{i j s}(\varphi) M_{i s} \mu_{i s}(\varphi) d \varphi$ is the total revenue associated with shipments from country $i$ to country $j$ in sector $s$. Third, free entry also implies that wage payments to labor equal total revenue in each country $i$ and sector $s$, that is, $w_{i} L_{i s}=\sum_{j=1,2} R_{i j s}$. These three steps lead immediately to:

$$
L_{i s}=\frac{1}{w_{i}} \sum_{j=1,2} R_{i j s}=M_{i s e} X_{i s}
$$

where $X_{i s} \equiv \theta_{s} F_{i s} / \rho_{s}$ is the labor demand per entrant in country $i$ and sector $s$. Notice that the industrial labor demand $L_{i s}$ depends only on the mass of entrants $M_{i s e}$ and not on any cut-off productivity levels $\varphi_{i j s}^{*}$. We will exploit this remarkable property to solve the model.

The second convenient property of the model is that we can solve for the mass of entrants $M_{1 s e}$ as a function of the wage $w_{1}$ and trade costs $\tau_{12 s}$ and $\tau_{21 s}$. Let $\phi_{i j s}$ denote the ratio of the expected profit of an entrant in country $i$ from selling to country $j$ in sector $s$ to that captured by an entrant in country $j$ from selling to country $j$ :

$$
\phi_{i j s} \equiv \frac{\delta_{i s}^{-1} \int_{\varphi_{i j s}^{*}}^{\infty}\left[\frac{r_{i j s}(\varphi)}{\sigma_{s}}-w_{i} f_{i j s}\right] d G_{i s}(\varphi)}{\delta_{j s}^{-1} \int_{\varphi_{j j s}^{*}}^{\infty}\left[\frac{r_{j j s}(\varphi)}{\sigma_{s}}-w_{j} f_{j j s}\right] d G_{j s}(\varphi)}
$$

Using (2), (5), (6) and (7), this relative expected profit simplifies to

$$
\phi_{i j s}=\frac{\delta_{j s} f_{i j s}}{\delta_{i s} f_{j j s}}\left(\frac{b_{i s}}{b_{j s}}\right)^{\theta_{s}} T_{i j s}^{-\theta_{s}}\left(\frac{w_{i}}{w_{j}}\right)^{1-\theta_{s} / \rho_{s}}
$$

so $\phi_{i j s}$ is a function of $\tau_{i j s}$ and $w_{1}$. From (2), (3), (4), (5), (6), (7), (8), (9), and (14), total revenue $R_{i j s}$ can be written as

$$
R_{i j s}=\alpha_{s} w_{j} L_{j} \frac{M_{i s e} \phi_{i j s}}{\sum_{k=1,2} M_{k s e} \phi_{k j s}} .
$$

From (13) and (15), we obtain

$$
\sum_{j=1,2} \alpha_{s} w_{j} L_{j} \frac{\phi_{i j s}}{\sum_{k=1,2} M_{k s e} \phi_{k j s}}=w_{i} X_{i s}
$$


For each sector $s$, (16) represents a system of linear equations that can be solved using Cramer's Rule for $M_{i s e}$. We find that the mass of entrants in country 1 and sector $s$ is

$$
M_{1 s e}=\alpha_{s}\left(\frac{w_{1} L_{1}}{w_{1} X_{1 s}-\phi_{12 s} X_{2 s}}-\frac{\phi_{21 s} L_{2}}{X_{2 s}-\phi_{21 s} w_{1} X_{1 s}}\right)
$$

Given (14), equation (17) defines $M_{1 s e}$ as a function of $w_{1}, \tau_{12 s}$ and $\tau_{21 s}$, and can be written in function form as $M_{1 s e}\left(w_{1}, \tau_{12 s}, \tau_{21 s}\right)$. As shown in the Appendix, this function has the following properties:

Lemma 1. The mass of entrants in sector $s$ in country $1, M_{1 s e}\left(w_{1}, \tau_{12 s}, \tau_{21 s}\right)$, satisfies:

$$
\frac{\partial M_{1 s e}}{\partial w_{1}}<0, \frac{\partial M_{1 s e}}{\partial \tau_{12 s}}<0 \text { and } \frac{\partial M_{1 s e}}{\partial \tau_{21 s}}>0
$$

Lemma 1 are quite intuitive. Increases in the wage $\left(w_{1} \uparrow\right)$ and export barriers $\left(\tau_{12 s} \uparrow\right)$ discourage entry $\left(M_{1 s e} \downarrow\right)$, while an increase in import barriers $\left(\tau_{21 s} \uparrow\right)$ encourages entry $\left(M_{1 s e} \uparrow\right)$.

Having already established that labor demand in country 1 is proportional to the mass of entrants $\left(L_{1 s}=M_{1 s e} X_{1 s}\right.$ ), it follows that labor demand in country 1 is a function of $w_{1}, \tau_{12 s}$ and $\tau_{21 s}$. This function can be written in function form as $L_{1 s}\left(w_{1}, \tau_{12 s}, \tau_{21 s}\right)$ and it has the same properties as the $M_{1 s e}\left(w_{1}, \tau_{12 s}, \tau_{21 s}\right)$ function: $\partial L_{1 s} / \partial w_{1}<0, \partial L_{1 s} / \partial \tau_{12 s}<0$ and $\partial L_{1 s} / \partial \tau_{21 s}>0$. In particular, we obtain the nice property that country 1 labor demand in each sector $(s=A$ and $s=B$ ) is downward sloping in the country 1 wage rate $w_{1}$. The country 1 labor supply is given by $L_{1}$ so the requirement that labor supply equals labor demand

$$
L_{1}=\sum_{s=A, B} L_{1 s}\left(w_{1}, \tau_{12 s}, \tau_{21 s}\right)
$$

uniquely determines the equilibrium wage rate $w_{1}$ given the trade costs $\left(\tau_{12 s}, \tau_{21 s}\right)$.

Figure 1 describes the determination of the equilibrium wage from (18) by using a graphical technique commonly used for the specific factors model. The vertical axis represents country 1's wage rate $w_{1}$ and the width of the box is set equal to country 1's labor endowment $L_{1}$. The left bottom corner represents the origin for sector $A$, while the right bottom corner represents the origin for sector $B$. The labor demand of each sector is drawn as a downward sloping curve relative to its corresponding origin. 
The intersection of the two curves determines the equilibrium wage and the allocation of labor across sectors.

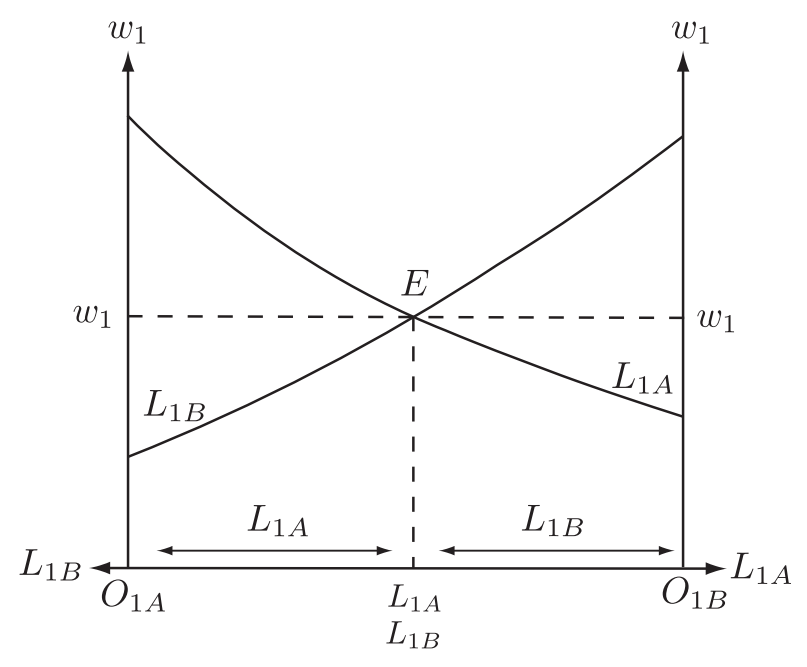

Figure 1: The labor market equilibrium

Having found the equilibrium wage rate $w_{1}$, we can now solve for the equilibrium cut-off productivity levels. From (7) and (11), we obtain the export productivity cut-off $\varphi_{12 s}^{*}$ for country 1 in sector $s$ as:

$$
\varphi_{12 s}^{*}=\left[\frac{\gamma_{1 s} f_{12 s}\left(1-\phi_{12 s} \phi_{21 s}\right)}{F_{2 s}\left(\phi_{12 s} / w_{1}\right)-\phi_{12 s} \phi_{21 s} F_{1 s}}\right]^{1 / \theta_{s}},
$$

where $\phi_{12 s} \phi_{21 s}<1$ from $f_{i j s}>f_{i i s}$. Given (14), equation (19) defines $\varphi_{12 s}^{*}$ as a function of $w_{1}, \tau_{12 s}$ and $\tau_{21 s}$, and can be written in function form as $\varphi_{12 s}^{*}\left(w_{1}, \tau_{12 s}, \tau_{21 s}\right)$. As shown in the Appendix, this function has the following properties: ${ }^{6}$

Lemma 2. The export productivity cutoff in sector s of country $1, \varphi_{12 s}^{*}\left(w_{1}, \tau_{12 s}, \tau_{21 s}\right)$ satisfies:

$$
\frac{\partial \varphi_{12 s}^{*}}{\partial w_{1}}>0, \frac{\partial \varphi_{12 s}^{*}}{\partial \tau_{12 s}}>0, \text { and } \frac{\partial \varphi_{12 s}^{*}}{\partial \tau_{21 s}}<0
$$

The first two effects in Lemma 2 are quite intuitive. When the wage rate increases $\left(w_{1} \uparrow\right)$ or the foreign import tariff increases $\left(\tau_{12 s} \uparrow\right)$, firms need to be more productive to justify exporting their products $\left(\varphi_{12 s}^{*} \uparrow\right)$. The last effect shows that the export productivity cut-off also rises $\left(\varphi_{12 s}^{*} \uparrow\right)$ when the domestic import tariff falls $\left(\tau_{21 s} \downarrow\right)$. Applying Lemma 1 for country 2 helps us to understand

\footnotetext{
${ }^{6}$ Demidova and Rodriguez-Clare (2013) show similar effects in a model with one industry.
} 
this effect. Because the tariff reduction by country 1 makes exports from country 2 more profitable, more firms enter the industry in country $2\left(\tau_{21 s} \downarrow \Rightarrow M_{2 s e} \uparrow\right)$. Since the industry in country 2 become more populated with firms, consumer demand for each individual firm's variety decreases in country 2. Therefore, firms in country 1 need to be more productive to justify exporting to country 2 .

For given levels of trade costs, Lemma 2 allows us to draw the positive relationship between the export productivity cutoff and the wage for country 1. Following Demidova and Rodriguez-Clare (2013), we refer to equation (19) as the "competitiveness curve" for country 1 and sector $s$. Figure 2 illustrates the competitiveness curves ( $C_{1 s}$ curves) for both sectors $s$ in country 1 together with the labor market diagram.

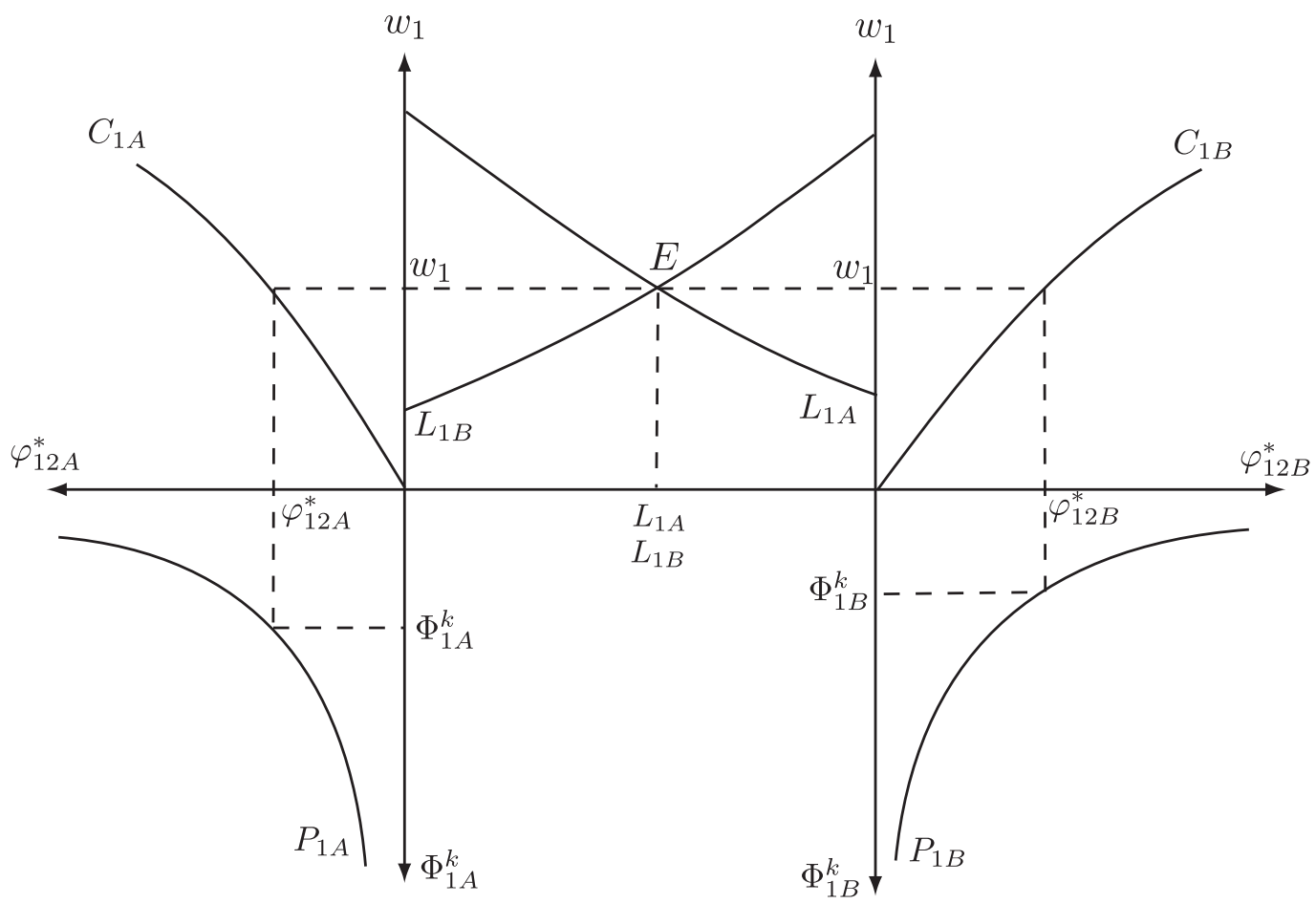

Figure 2: Determination of the equilibrium

Finally, we show that industrial productivity only depends on the export productivity cut-off. We consider three measures of industrial productivity. The first measure of industrial productivity $\Phi_{1 s}^{R}$ is defined as the industrial average of firm productivity weighted by each firm's revenue share in the 
industry:

$$
\Phi_{1 s}^{R} \equiv \int_{0}^{\infty} \varphi v_{1 s}(\varphi) d \varphi \quad \text { where } \quad v_{1 s}(\varphi) \equiv \frac{\sum_{j=1,2} I\left(\varphi \geq \varphi_{1 j s}^{*}\right) r_{1 j s}(\varphi) M_{1 s} \mu_{1 s}(\varphi)}{\sum_{k=1,2} R_{1 k s}}
$$

In this definition, $I\left(\varphi \geq \varphi_{1 j s}^{*}\right)$ is an indicator function that takes on the value 1 if $\varphi \geq \varphi_{1 j s}^{*}$ and 0 otherwise. The function $v_{1 s}(\varphi)$ is a revenue-weighted density function for $\varphi$ and satisfies $\int_{0}^{\infty} v_{1 s}(\varphi) d \varphi=1$. We need to assume $\theta_{s}>\sigma_{s}$ so that $\Phi_{1 s}^{R}$ takes a finite value. This measure is widely used in empirical studies (e.g. Olley and Pakes, 1996) and is a simpler version of the measure that Melitz (2003) used. The second measure of industrial productivity $\Phi_{1 s}^{L}$ is industrial labor productivity defined as the real industrial output per unit of labor:

$$
\Phi_{1 s}^{L}=\frac{\left(\sum_{j=1,2} R_{1 j s}\right) / \tilde{P}_{1 s}}{L_{1 s}} .
$$

In this definition, the price deflator $\tilde{P}_{1 s} \equiv \int_{\varphi_{11 s}^{*}}^{\infty} p_{11 s}(\varphi) \mu_{1 s}(\varphi) d \varphi$ is the simple average of prices set by domestic firms at the factory gate and aims to resemble the industrial product price index, which is used for the calculation of the real industrial output. This measure is also widely used in empirical studies (e.g. Trefler, 2004). The third measure of industrial productivity $\Phi_{1 s}^{W}$ is industrial labor productivity calculated using the theoretically consistent "exact" price index $P_{1 s}$ that we derived earlier in equation (9):

$$
\Phi_{1 s}^{W}=\frac{\left(\sum_{j=1,2} R_{1 j s}\right) / P_{1 s}}{L_{1 s}} .
$$

This measure is motivated by thinking about consumer welfare. Consider the representative consumer in country 1 who supplies one unit of labor. Since her utility $U_{1}$ satisfies

$$
U_{1}=\left(\alpha_{A} \Phi_{1 A}^{W}\right)^{\alpha_{A}}\left(\alpha_{B} \Phi_{1 B}^{W}\right)^{\alpha_{B}}
$$

$\Phi_{1 A}^{W}$ and $\Phi_{1 B}^{W}$ are the productivity measures for industries $A$ and $B$ that are directly relevant for calculating consumer welfare $U_{1}$.

The next lemma shows that, regardless of which measure of industrial productivity we use, we can draw a negative-sloped curve between industrial productivity and the export productivity cut-off, and 
this curve does not shift as a result of changes in the wage $w_{1}$ or variable trade costs.

Lemma 3. All three measures of industrial productivity $\Phi_{1 s}^{k}(k=R, L, W)$ can be expressed as decreasing functions of the export productivity cut-off $\varphi_{12 s}^{*}$ and these functions $\Phi_{1 s}^{k}\left(\varphi_{12 s}^{*}\right)$ do not contain any other endogenous variables or variable trade costs. ${ }^{7}$

The proof of Lemma 3 is presented in the Appendix. We focus here on explaining the intuition behind Lemma 3 using the revenue-weighted productivity measure $\Phi_{1 s}^{R}$. Suppose the export productivity cut-off falls from $\varphi_{12 s}^{* 0}$ to $\varphi_{12 s}^{* 1}$, as shown in Figure 3. This means that exporting becomes more profitable for some firms in country 1 that could not previously afford to pay the exporting fixed cost $w_{1} f_{12 s}$. Since all exporters face the same demand function and the same level of trade barriers, exporting must become more profitable for existing exporters also. It follows that a potential entrant in country 1 sees an increase in the expected profits from entry and more firms enter the industry in country 1 . Some of these new entrants draw sufficiently high productivities to survive. This means that the industry becomes more populated with firms and local consumer demand for each individual firm's product decreases. ${ }^{8}$ Thus, all firms earn lower profits from domestic sales and the lowest productivity non-exporting firms exit, that is, the domestic productivity cut-off increases from $\varphi_{11 s}^{* 0}$ to $\varphi_{11 s}^{* 1}$, as shown in Figure 3. The decrease in the expected profits from domestic sales just offsets the increase in the expected profits from export sales.

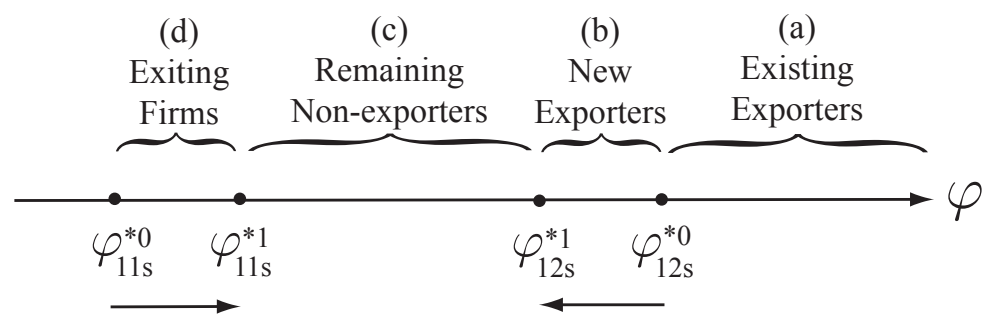

Figure 3: When the export productivity cut-off falls, the domestic productivity cut-off rises.

\footnotetext{
${ }^{7}$ Some might wonder how we can draw a curve showing industrial productivity as a function of the export productivity cutoff, given both industrial productivity and the export productivity cutoff are endogenous variables. What we do here is similar to drawing a production possibility frontier in the $2 \times 2$ Heckscher-Ohlin model. Though outputs are endogenous in the Heckscher-Ohlin model, we can draw a production possibility frontier by considering what the output of one good would be if the output of the other good is fixed at a hypothetical level.

${ }^{8}$ The decrease in local consumer demand can be confirmed as follows. By using $\Phi_{1 s}^{W}=w_{1} / P_{1 s}$ in the proof of Lemma 3 , (4) and (5), local consumer demand for an individual firm can be written as $q_{11 s}(\varphi)=\left(\rho_{s} \varphi\right)^{\sigma_{s}}\left(\Phi_{1 s}^{W}\right)^{1-\sigma_{s}} \alpha_{s} L_{1}$. Therefore, local demand $q_{11 s}(\varphi)$ falls if and only if productivity $\Phi_{1 s}^{W}$ rises.
} 
To understand how resources are reallocated within an industry, it is helpful to think about four groups of firms: (a) "existing exporters" with productivity $\varphi \in\left[\varphi_{12 s}^{* 0}, \infty\right)$, (b) "new exporters" with productivity $\varphi \in\left[\varphi_{12 s}^{* 1}, \varphi_{12 s}^{* 0}\right)$, (c) "remaining non-exporters" with productivity $\varphi \in\left[\varphi_{11 s}^{* 1}, \varphi_{12 s}^{* 1}\right)$ and (d) "exiting firms" with productivity $\varphi \in\left[\varphi_{11 s}^{* 0}, \varphi_{11 s}^{* 1}\right)$. In response to a decrease in $\varphi_{12 s}^{*}$, the free entry condition implies that the total increase in revenue shares of existing exporters is exactly balanced by the total decrease in revenue shares of remaining non-exporters. Since the changes in the revenue shares of the four groups add up to zero, it follows that the total increase in revenue shares of new exporters is exactly balanced by the total decrease in revenue shares of exiting firms. Therefore, revenue shares are reallocated from group (c) to group (a) and from group (d) to group (b). Since exporters (a) and (b) are more productive than non-exporters (c) and (d), resources are reallocated from less to more productive firms, increasing industrial productivity $\Phi_{1 s}^{R} .{ }^{9}$

An important implication of Lemma 3 is that the source of a rise in industrial productivity in the Melitz model is higher profits from exporting. For liberalization of variable trade costs, whether it is multilateral or unilateral, the necessary and sufficient condition for industrial productivity to rise is that the export productivity cut-off falls, that is, exporting becomes more profitable.

Using Lemma 3, we draw the negative relationship between $\varphi_{12 s}^{*}$ and $\Phi_{1 s}^{k}$ for each sector $s$ in the bottom two diagrams in Figure $2(k=R, L, W)$. We refer to the $\Phi_{1 s}^{k}\left(\varphi_{12 s}^{*}\right)$ functions as "productivity curves" and label them as $P_{1 s}$ curves in Figure 2. Factor market clearing determines $w_{1}$, then the competitiveness curves determine $\varphi_{12 s}^{*}$ and then the productivity curves determine $\Phi_{1 s}^{k}{ }^{10}$

\section{Trade Liberalization}

We are now ready to analyze the impact of trade liberalization on industrial productivity. While Melitz (2003) considered only multilateral and uniform liberalization, in which all countries reduce variable trade costs on all products in a uniform way, we consider unilateral and non-uniform liberalization: country 1 liberalizes tariffs only for sector $A$. Following Melitz (2003), import tariffs take the form of

\footnotetext{
${ }^{9}$ We thank Don Davis for his suggestion of thinking about four groups of firms.

${ }^{10}$ The weighted average productivity measure in Melitz (2003), $\tilde{\varphi}_{1 s} \equiv\left[\int_{\varphi_{11 s}^{*}}^{\infty} \varphi^{\sigma_{s}-1} \mu_{1 s}(\varphi) d \varphi\right]^{1 /\left(\sigma_{s}-1\right)}=$ $\left[\theta_{s} /\left(\theta_{s}-\sigma_{s}+1\right)\right]^{1 /\left(\sigma_{s}-1\right)} \varphi_{11 s}^{*}$ also satisfies Lemma 3. Since $\varphi_{11 s}^{*}$ and $\varphi_{12 s}^{*}$ move in the opposite direction from (11), productivity $\tilde{\varphi}_{1 s}$ rises if and only if $\varphi_{12 s}^{*}$ falls. Since $w_{1}$ and $\tau_{i j s}$ do not show up in either $\tilde{\varphi}_{1 s}$ or (11), they affect $\tilde{\varphi}_{1 s}$ only through $\varphi_{12 s}^{*}$.
} 
iceberg trade costs. So trade liberalization for us means decreasing $\tau_{21 A}$ while holding $\tau_{12 A}, \tau_{12 B}$ and $\tau_{21 B}$ fixed. We call sector $A$ the liberalized industry and sector $B$ the non-liberalized industry.

\subsection{Structurally Symmetric Industries}

We focus on the impact of trade liberalization when the two industries are structurally symmetric except for their consumption share in GDP ( $\alpha_{A}$ is allowed to differ from $\left.\alpha_{B}\right)$.

Definition 1. The two industries are structurally symmetric if $\rho_{A}=\rho_{B}, \theta_{A}=\theta_{B}, \delta_{i A}=\delta_{i B}$, $b_{i A}=b_{i B}, f_{i j A}=f_{i j B}, F_{i A}=F_{i B}$, and $\tau_{i j A}=\tau_{i j B}$.

This is a natural benchmark case for the analysis of unilateral and non-uniform trade liberalization. The Melitz (2003) model only has one industry but requires balanced trade and labor market clearing as in general equilibrium models. Thus, it is natural to think of the one industry in the Melitz model as a representative industry. Note that Definition 1 requires symmetry only across industries. Countries can differ in their factor endowments, technologies and trade costs.

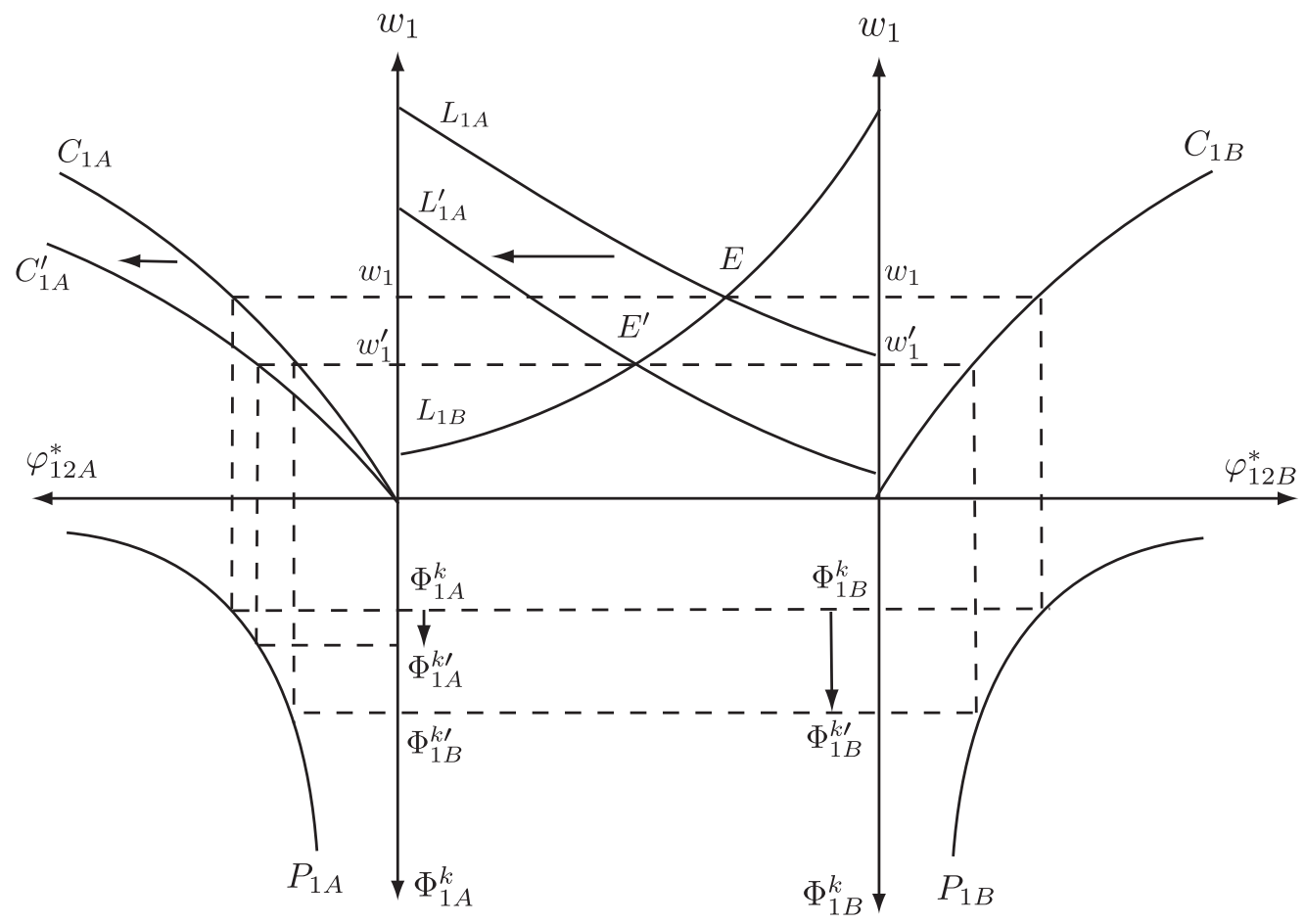

Figure 4: Productivity rises more strongly in the non-liberalized industry 
The diagrams developed in the previous section greatly simplifies the analysis. Figure 4 shows the same diagrams we used in Figure 2 for the structurally symmetric industries case. Before trade liberalization, both industries have symmetric competitiveness curves (the $C_{1 A}$ and $C_{1 B}$ curves) and symmetric productivity curves (the $P_{1 A}$ and $P_{1 B}$ curves), which implies that both industries have the same productivity $\Phi_{1 A}^{k}=\Phi_{1 B}^{k}(k=R, L, W) .{ }^{11}$

Results derived in the previous section imply that two curves shift in Figure 4 when the tariff for industry $A$ falls in country 1 . From Lemma 1 , the labor demand curve of the liberalized industry $A$ shifts leftward (curve $L_{1 A}$ shifts to $L_{1 A}^{\prime}$ ) since the mass of entrants drops for a given wage level $w_{1}$ $\left(\tau_{21 A} \downarrow \Rightarrow M_{1 A e} \downarrow, L_{1 A} \downarrow\right)$. From Lemma 2, the competitiveness curve of the liberalized industry $A$ shifts leftward (curve $C_{1 A}$ shifts to $C_{1 A}^{\prime}$ ) for a given wage level $w_{1}\left(\tau_{21 A} \downarrow \Rightarrow \varphi_{12 A}^{*} \uparrow\right.$ ), while the competitiveness curve of the non-liberalized industry $B$ does not shift. We refer to the shift in the labor demand curve as the wage effect and the shift in the competitiveness curve as the competitiveness effect. To understand the overall effect of trade liberalization, we consider the wage effect and the competitiveness effect one at a time.

First, we consider the competitiveness effect. Figure 5 shows only the shift of the $C_{1 A}$ curve by fixing the $L_{1 A}$ curve at the pre-liberalization position. As the $C_{1 A}$ curve shifts in the top-left diagram, the export productivity cutoff rises in the liberalized industry but does not change in the non-liberalize industry. The bottom-left and the bottom-right diagrams show that productivity falls in the liberalized industry but does not change in the non-liberalized industry $\left(\Delta \Phi_{1 A}^{k}<0=\Delta \Phi_{1 B}^{k}\right)$. The intuition for the competitiveness effect follows from our earlier discussion of Lemma 2 and Lemma 3. Because trade liberalization by country 1 in industry $A$ increases the exporting profits of country 2 firms, more firms enter in country 2 and it becomes less profitable for country 1 firms to export to the now more competitive country 2 market. Therefore, in the liberalized industry $A$, country 1 resources are reallocated from exporters to non-exporters, decreasing industrial productivity ( $\left.\varphi_{12 A}^{*} \uparrow \Rightarrow \Phi_{1 A}^{k} \downarrow\right)$.

Second, we consider the wage effect. Figure 6 shows only the shift of the $L_{1 A}$ curve by fixing the $C_{1 A}$ curve at the pre-liberalization position. As the labor demand curve of the liberalized industry $A$ shifts leftward in the top-center diagram, workers move from the liberalized industry $A$ to the nonliberalized industry $B$ and the wage decreases in the liberalizing country. In the top-left and the top-

\footnotetext{
${ }^{11}$ Before liberalization, country 1 always produce positive outputs in both sectors since $L_{1 A} / \alpha_{A}=L_{1 B} / \alpha_{B}$ holds from (13) and (17).
} 


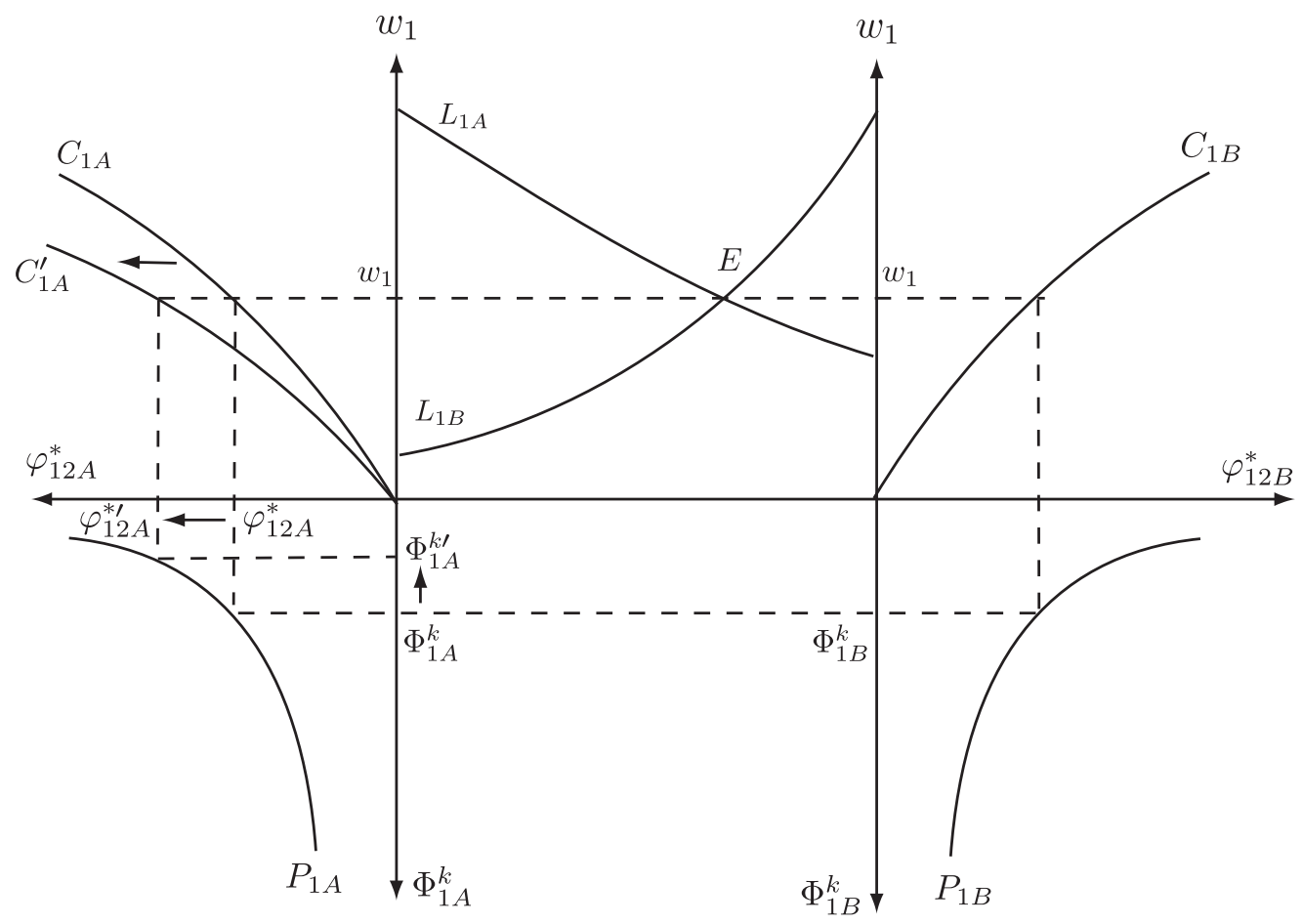

Figure 5: The competitiveness effect decreases productivity in the liberalized industry

right diagrams, as country 1's wage $w_{1}$ decreases, the export productivity cut-offs decrease in both industries. The bottom-left and the bottom-right diagrams show that productivity increases equally in both industries $\left(\Delta \Phi_{1 A}^{k}=\Delta \Phi_{1 B}^{k}>0\right)$.

To understand the wage effect, it is helpful to think about the balanced trade condition. Let $E_{i j s}$ be the expenditure of country $i$ on country $j$ goods in sector $s$. Then the exports in sector $s$ by country 1 is $\sum_{j=1,2} R_{1 j s}-E_{11 s}$ and the imports in sector $s$ by country 1 is $E_{12 s}$. The balanced trade condition can be written as

$$
\sum_{s=A, B}\left[\left(\sum_{j=1,2} R_{1 j s}-E_{11 s}\right)-E_{12 s}\right]=0
$$

From $\sum_{j=1,2} R_{1 j s}=w_{1} L_{1 s}$ and $\sum_{j=1,2} E_{1 j s}=\alpha_{s} w_{1} L_{1}$, the excess exports of sector $s$ can be expressed as

$$
\left(\sum_{j=1,2} R_{1 j s}-E_{11 s}\right)-E_{12 s}=w_{1} \alpha_{s}\left(\frac{L_{1 s}\left(w_{1}, \tau_{12 s}, \tau_{21 s}\right)}{\alpha_{s}}-L_{1}\right) .
$$

By summing up (25) for both industries, we see that the balanced trade condition (24) is equivalent to 


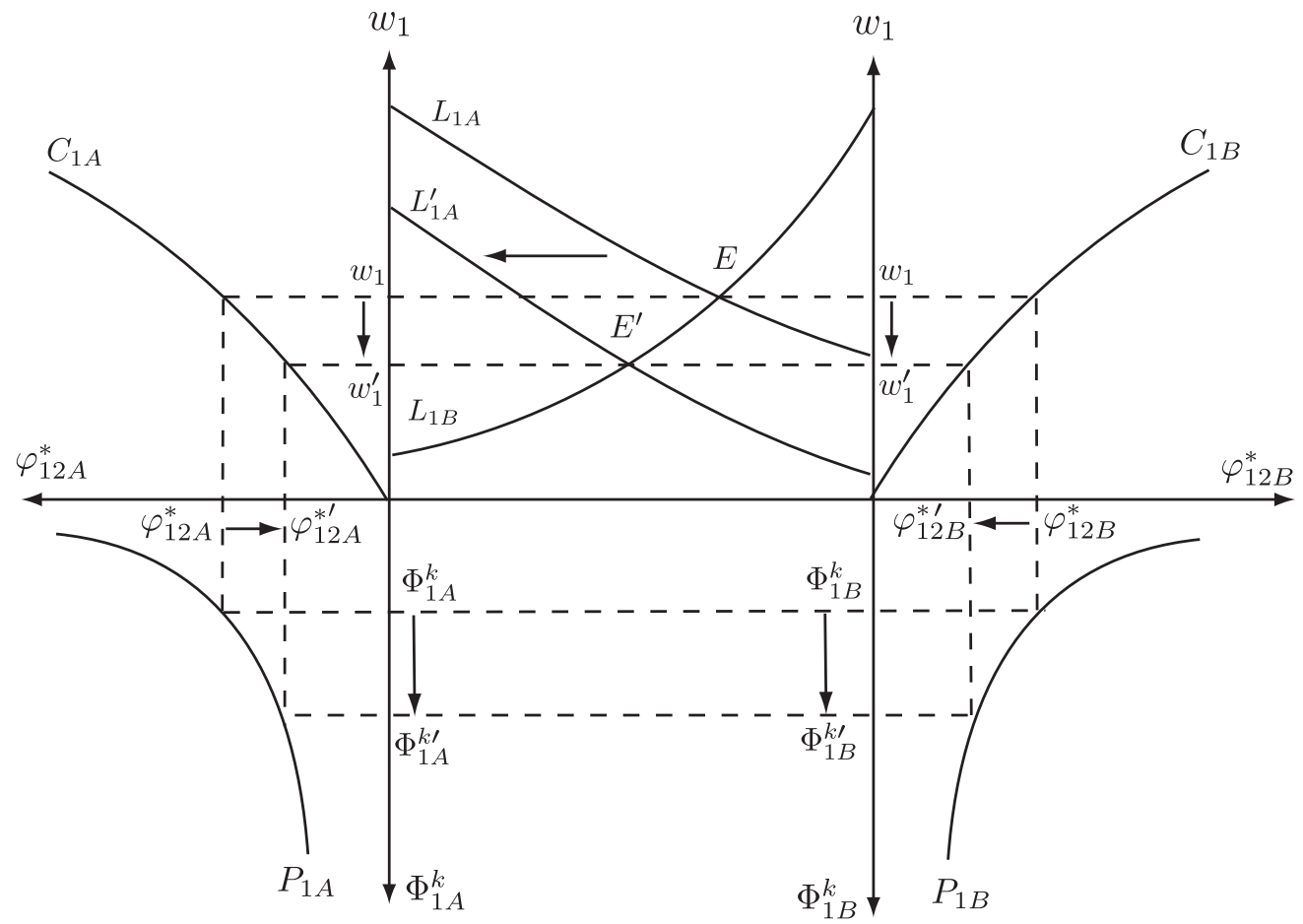

Figure 6: The wage effect increases productivity in both industries

the labor market clearing condition (18).

Starting from balanced trade and holding the wage $w_{1}$ fixed, trade liberalization leads to excess imports in industry $A$ by the liberalizing country 1 . Then (24) and (25) imply that the wage $w_{1}$ must drop to increase exports by both industries in the liberalizing country until trade balance is restored. Since exports increase not only for existing exporters (the intensive margin) but also by the entry of less productive firms into exporting (the extensive margin), the export productivity cut-offs $\varphi_{12 s}^{*}$ fall in both industries when $w_{1}$ falls. Because exporting becomes more profitable, resources are reallocated from non-exporting firms to exporting firms, increasing industrial productivity. With structurally symmetric industries, the wage effect by itself contributes to increase productivity equally in both industries.

The effects of trade liberalization on industrial productivity are summarized in Table 2 . The wage effect tends to increase productivity in both industries symmetrically, while the competitiveness effect tends to decrease productivity in the liberalized industry. As a consequence, industrial productivity unambiguously rises in the non-liberalized industry $B$ but it can rise or fall in the liberalized industry $A$, depending on the relative size of the wage effect and the competitiveness effect. Figure 4 illustrates 


\begin{tabular}{cccc}
\cline { 2 - 4 } & \multicolumn{3}{c}{ Impact on Industrial Productivity } \\
\cline { 2 - 4 } & Liberalized $(A)$ & Non-liberalized $(B)$ & Difference \\
& $\Delta \Phi_{1 A}^{k}$ & $\Delta \Phi_{1 B}^{k}$ & $\Delta \Phi_{1 A}^{k}-\Delta \Phi_{1 B}^{k}$ \\
\hline Competitiveness Effect & - & 0 & - \\
Wage Effect & + & + & 0 \\
\hline \hline Total Effect & + or - & + & - \\
\hline \hline
\end{tabular}

Table 2: The effects of trade liberalization

the case where the wage effect of trade liberalization dominates the competitiveness effect, with the consequence that productivity rises in the liberalized industry. We have established

Theorem 1. In the multi-industry Melitz model with structurally symmetric industries, unilateral trade liberalization by country 1 in industry $A\left(\tau_{21 A} \downarrow\right)$ leads to a decrease in the country 1 wage rate $\left(w_{1} \downarrow\right)$ and an increase in the productivity of the non-liberalized industry $\left(\Phi_{1 B}^{k} \uparrow\right)$. However, whether productivity rises or falls in the liberalized industry is in general ambiguous $\left(\Phi_{1 A}^{k} \uparrow\right.$ or $\left.\downarrow\right)$.

Although trade liberalization has an ambiguous effect on productivity in the liberalized industry, we can make an unambiguous statement about the difference in the productivity change between the liberalized and the non-liberalized industries. The wage effect tends to increase productivity in both industries symmetrically, while the competitiveness effect tends to decrease productivity only in the liberalized industry. Thus, productivity rises more strongly in the non-liberalized industry than in the liberalized industry, i.e. $\Delta \Phi_{1 B}^{k}-\Delta \Phi_{1 A}^{k}>0, k=R, L, W$. This "difference-in-difference" prediction is sufficient for our purpose of matching the model with empirical studies. Because typical empirical studies estimate cross-industry regressions with time fixed effects and industry fixed effects (e.g. Trefler, 2004), their estimates only tell us whether trade liberalization increases productivity in liberalized industries relative to non-liberalized industries. We have established

Theorem 2. In the multi-industry Melitz model with structurally symmetric industries, unilateral trade liberalization by country 1 in industry $A\left(\tau_{21 A} \downarrow\right)$ leads to productivity rising more strongly in the nonliberalized industry than in the liberalized industry $\left(\Delta \Phi_{1 B}^{k}>\Delta \Phi_{1 A}^{k}\right.$ for $\left.k=R, L, W\right)$.

Theorem 2 is our central result. An empirical finding by Trefler (2004) and others that industrial productivity increases more strongly in liberalized industries than in non-liberalized industries has been widely accepted as evidence for the Melitz (2003) model. Theorem 2 shows that a multi-industry 
version of the Melitz model does not predict this relationship. Instead, it predicts the opposite relationship that industrial productivity increases more strongly in non-liberalized industries than in liberalized industries. Theorem 2 forces us to re-think the match between theory and evidence: an empirical fact that has been widely cited as evidence for the Melitz model is actually evidence against the Melitz model.

Next, we study whether the effects of trade liberalization depend on the size of the industry that opens up to trade. Does trade liberalization have different effects, depending on whether the liberalized industry is small or large? Since the parameter $\alpha_{s}$ determines the size of industry $s$, we analyze how the response of industrial productivity to trade liberalization depends on $\alpha_{A}$, the size of the liberalized industry.

Holding all other parameter values fixed, a change in $\alpha_{A}$ has no effect on the equilibrium wage $w_{1}$. Since employment in the two industries satisfies $L_{1 A} / \alpha_{A}=L_{1 B} / \alpha_{B}$ from (13) and (17), the labor market clearing condition (18) can be rewritten as

$$
L_{1}=L_{1 A}+L_{1 B}=L_{1 A}\left(\frac{\alpha_{A}+\alpha_{B}}{\alpha_{A}}\right)=\frac{L_{1 A}}{\alpha_{A}}
$$

Now $L_{1}=L_{1 A}\left(w_{1}, \tau_{12 s}, \tau_{21 s}\right) / \alpha_{A}$ uniquely determines the equilibrium wage $w_{1}$ and $L_{1 A} / \alpha_{A}$ does not depend on $\alpha_{A}$ from (17). Thus, the equilibrium wage $w_{1}$ does not depend on $\alpha_{A}$.

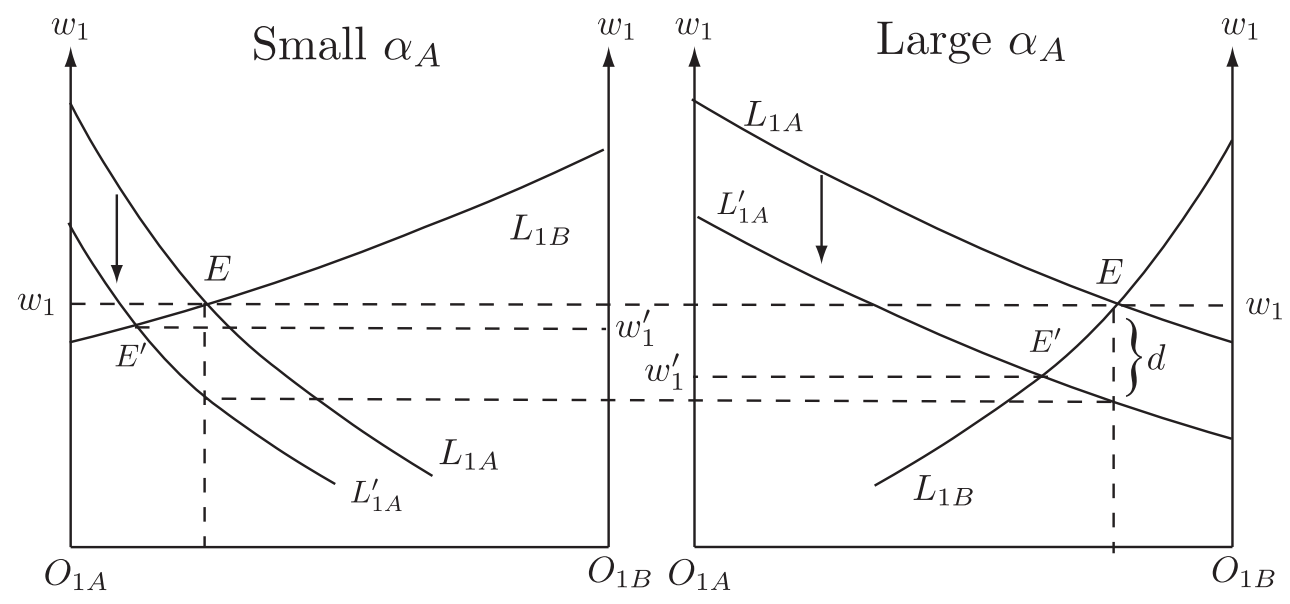

Figure 7: How much the wage declines depends on the size of the liberalized industry

As illustrated in Figure 7, the pre-liberalization wage $w_{1}$ is the same whether $\alpha_{A}$ is small or large. 
Trade liberalization causes the labor demand curve $L_{1 A}$ to shift leftward, or equivalently, to shift down. Equation (17) implies that the size of the downward shift in the labor demand curve $L_{1 A}$ (" $d$ " in Figure 7) does not depends on $\alpha_{A}$. Equation (17) also implies that as $\alpha_{A}$ increases, the slope of the labor demand curve $L_{1 A}$ becomes flatter because the number of entrants in industry $A$ increases in $\alpha_{A}$. Similarly, as $\alpha_{A}$ increases, which means that $\alpha_{B}=1-\alpha_{A}$ decreases, the slope of the labor demand curve $L_{1 B}$ becomes steeper. Thus, as illustrated in Figure 7, the wage drop due to trade liberalization is larger when $\alpha_{A}$ is larger.

Figure 4 shows that whether productivity increases in the liberalized industry $A$ depends on the net effect of the wage effect and the competitiveness effect. The competitiveness effect does not depend on $\alpha_{A}$ since equation (19) does not include $\alpha_{A}$. However, as we have just shown, the wage effect is larger when $\alpha_{A}$ is larger. If $\alpha_{A}$ is sufficiently small and the wage effect is sufficiently small, then the competitiveness effect must dominate the wage effect. Figure 8 illustrates this case. The export

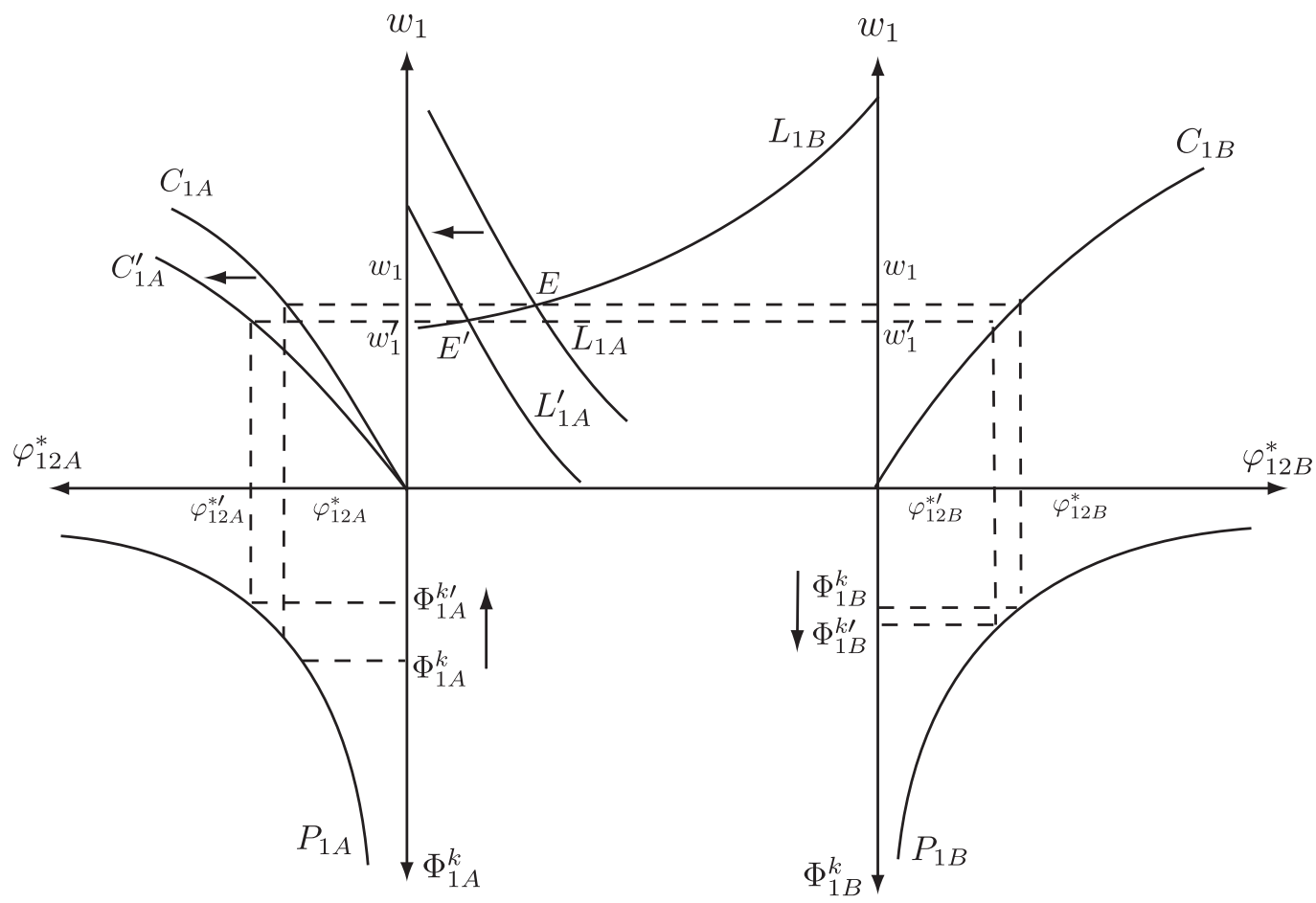

Figure 8: Productivity falls in the liberalized industry if the liberalized industry is small

productivity cut-off $\varphi_{12 A}^{*}$ rises and productivity $\Phi_{1 A}^{k}$ unambiguously falls in the liberalized industry. If $\alpha_{A}$ is sufficiently large and satisfies $\alpha_{A}=1$, then the model reduces to a one industry Melitz 
model where Demidova and Rodriguez-Clare (2013) proved that unilateral liberalization raises industrial productivity. [Strictly speaking, Demidova and Rodriguez-Clare (2013) proved that unilateral trade liberalization raises the welfare of the liberalizing country for the case of $\alpha_{A}=1$. However, when $\alpha_{A}=1$, (23) implies that welfare equals industrial productivity $\left(U=\Phi_{1 A}^{W}\right)$, so changes in welfare correspond to changes in industrial productivity.] Since the model's properties are continuous in parameter $\alpha_{A}$, we obtain the following theorem:

Theorem 3. In the multi-industry Melitz model with structurally symmetric industries, suppose that there is unilateral trade liberalization by country 1 in industry $A\left(\tau_{21 A} \downarrow\right)$. Then there exists a threshold $\bar{\alpha}_{A} \in(0,1)$ such that productivity $\Phi_{1 A}^{k}$ falls in the liberalized industry if $\alpha_{A}<\bar{\alpha}_{A}$ and rises if $\alpha_{A}>\bar{\alpha}_{A}$.

Demidova and Rodriguez-Clare (2013) and Felbermayr, Jung, and Larch (2013) find that unilateral trade liberalization unambiguously raises the productivity of the liberalized industry. Theorem 3 shows that their results depend on the strong assumption that the economy just has one industry $\left(\alpha_{A}=1\right)$. In a setting with more than one industry, unilateral trade liberalization lowers industrial productivity if the liberalized industries account for only a small share of GDP ( $\alpha_{A}$ small).

By combining the results in Theorems 1 and 3, we obtain one more theorem:

Theorem 4. In the multi-industry Melitz model with structurally symmetric industries, suppose that there is unilateral trade liberalization by country 1 in industry $A\left(\tau_{21 A} \downarrow\right)$. If $\alpha_{A}$ is sufficiently small, then productivity falls in the liberalized industry $A$ and rises in the non-liberalized industry $B\left(\Phi_{1 A}^{k} \downarrow\right.$ and $\left.\Phi_{1 B}^{k} \uparrow\right)$.

Theorem 4 provides a surprising policy implication. If the government of a country is interested in raising the productivity of a small "target" industry through a resource reallocation from less productive to more productive firms, the theoretically correct advice based on the Melitz model is to protect the target industry, not trade liberalization. This is obviously the opposite of the policy recommendation that is suggested by Trefler (2004) and other empirical studies. 


\subsection{Symmetric Multilateral Trade Liberalization}

In this subsection, we replicate the analysis of symmetric multilateral trade liberalization in Melitz (2003) using our diagrams. The two countries are assumed to be identical as in Melitz (2003) but each industry may have different parameters. We analyze multilateral but non-uniform liberalization by decreasing $\tau_{12 A}$ and $\tau_{21 A}$ by the same amount while holding $\tau_{12 B}$ and $\tau_{21 B}$ fixed.

Assuming symmetric countries simplifies the model. First, wages are equalized between the two countries: $w_{1}=w_{2}=1$. Second, the notation for describing the model takes a simpler form: $X_{i s}=$ $X_{s}, \phi_{i j s}=\phi_{s}, T_{i j s}=T_{s}, F_{i s}=F_{s}, f_{i i s}=f_{s}$ and $f_{i j s}=f_{x s}$ for $i \neq j$.

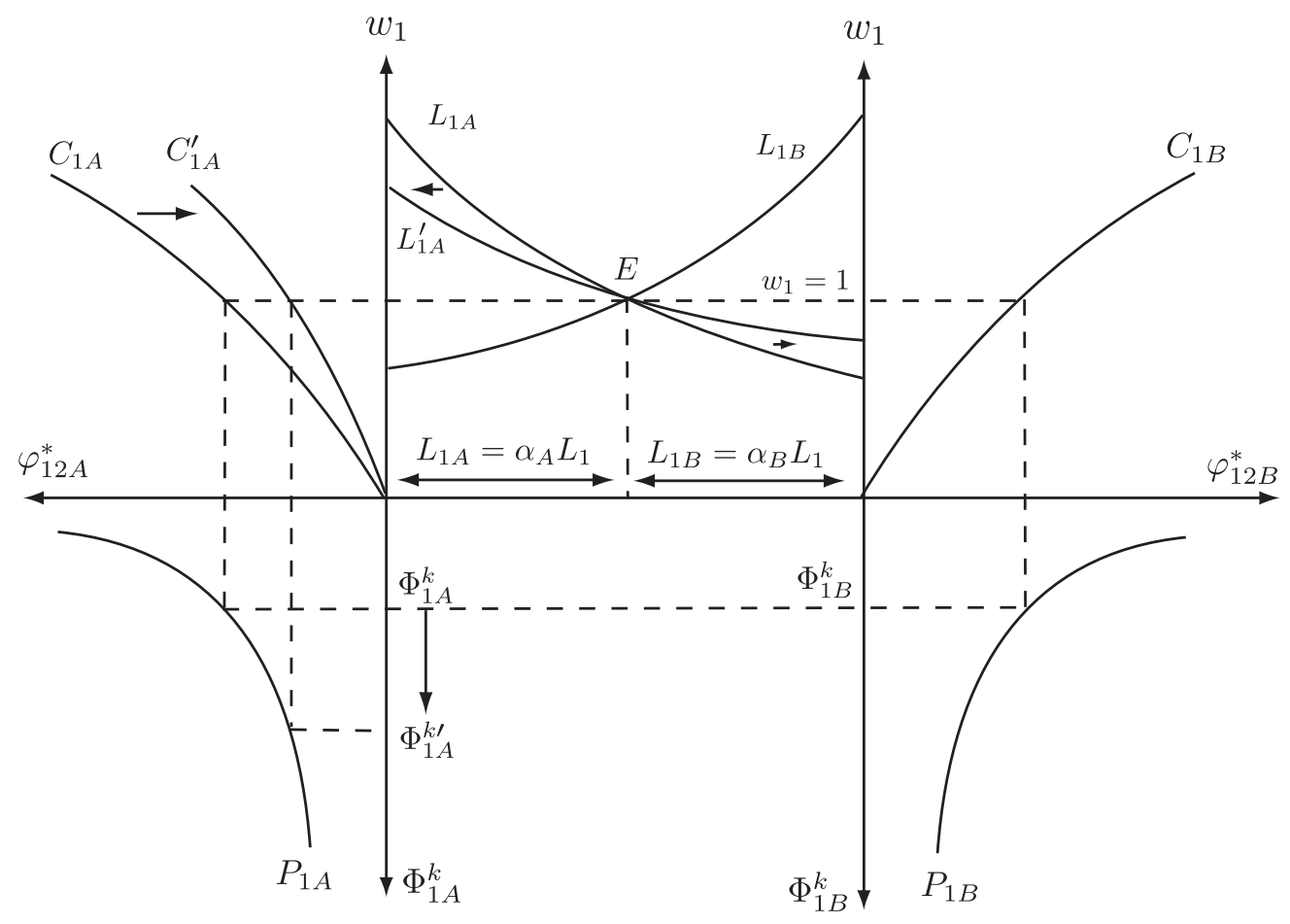

Figure 9: Multilateral trade liberalization in industry $A$

Figure 9 describes the impact of liberalization. The employment in sector $s$ becomes $L_{1 s}=$ $\alpha_{s} L_{1}$ from (13) and (17), so multilateral trade liberalization in sector $A\left(\tau_{12 A}=\tau_{21 A} \downarrow\right)$ leads to no equilibrium change in the wage $w_{1}$ and the labor allocation. ${ }^{12}$ The top-right and bottom-right diagrams show that multilateral liberalization does not affect productivity $\Phi_{1 B}^{k}$ in the non-liberalized industry.

\footnotetext{
${ }^{12}$ The labor demand curve of the liberalized industry becomes flatter as illustrated in Figure 9. This is shown in the Appendix.
} 
The impact on the liberalized industry is different from the case of unilateral trade liberalization. Given symmetric countries, the export productivity cut-off in sector $A$ [given by (19)] simplifies to

$$
\varphi_{12 A}^{*}=\left[\frac{\gamma_{1 A} f_{x A}}{F_{A}}\left(1+\frac{1}{\phi_{A}}\right)\right]^{1 / \theta_{A}}
$$

and (14) implies that $\phi_{A}=\left(f_{x A} / f_{A}\right) T_{A}^{-\theta_{A}}$. Thus multilateral trade liberalization leads to a decrease in the export productivity cut-off $\varphi_{12 A}^{*}$ and an increase in productivity $\Phi_{1 A}^{k}$ in the liberalized industry. We have established

Theorem 5. In the multi-industry Melitz model with symmetric countries, symmetric multilateral trade liberalization $\left(\tau_{12 A}=\tau_{21 A} \downarrow\right)$ increases productivity in the liberalized industry $\left(\Phi_{1 A}^{k} \uparrow\right)$ but not in the non-liberalized industry $\left(\Phi_{1 B}^{k}\right.$ unchanged $)$.

A comparison of Theorems 2 and 5 confirms that the source of the rise in industrial productivity in the Melitz model is the expansion of export opportunity, not the increased import competition from trade liberalization.

Notice that by setting $\alpha_{A}=1$, the model becomes identical to the original Melitz (2003) model with one industry. Therefore, our analysis nests the analysis of multilateral and uniform liberalization in Melitz (2003). We obtain Melitz's original result using new diagrams:

Corollary 1. (Melitz, 2003) If there is only one industry $\left(\alpha_{A}=1\right)$ and symmetric countries, then symmetric multilateral trade liberalization $\left(\tau_{12 A}=\tau_{21 A} \downarrow\right)$ increases industrial productivity $\left(\Phi_{1 A}^{k} \uparrow\right)$.

\subsection{Numerical Results}

As a check that our analytically derived results are correct, we also solve the model numerically. Looking at a numerical example is helpful for understanding the intuition behind the results. ${ }^{13}$

For the numerical results reported in Table 3, we assume structurally symmetric industries and countries. Then there are only ten parameters that need to be chosen. We use the following benchmark parameter values: $\sigma_{s}=3.8, \delta_{i s}=.025, b_{i s}=.2, \theta_{s}=4.582, F_{i s}=2, f_{i i s}=.043, L_{i}=1$,

\footnotetext{
${ }^{13}$ The MATLAB files used to solve the model can be obtained from the authors upon request.
} 
$\alpha_{A}=.5, \tau_{i j s}=1.3$ and $f_{i j s}=.0588$. The first six parameter values come from Balistreri, Hillbery and Rutherford (2011), where a version of the Melitz model is calibrated to fit trade data. $L_{i}=1$ is a convenient normalization given that an increase in country size $L_{i}$ has no effect on the key endogenous variables that we are solving for (the relative wage $w_{1} / w_{2}$, productivity cutoff levels $\varphi_{i j s}^{*}$ and industry productivity levels $\left.\Phi_{i s}^{R}\right) . \alpha_{A}=.5$ means that both industries are equally large: consumers spend 50 percent of their income on industry A products and 50 percent of their income on industry B products. $\tau_{i j s}=1.3$ corresponds to a 30 percent tax on all traded goods. Finally, we chose $f_{i j s}=.0588$ to guarantee that 18 percent of firms export in our benchmark equilibrium, consistent with evidence for the United States (Bernard et al., 2007).

\begin{tabular}{c||c|c||c|c||}
\hline \hline \multicolumn{1}{c||}{} & \multicolumn{2}{c||}{$\alpha_{A}=.5$ Case } & \multicolumn{2}{c||}{$\alpha_{A}=.3$ Case } \\
\hline & $\tau_{21 A}=1.30$ & $\tau_{21 A}=1.15$ & $\tau_{21 A}=1.30$ & $\tau_{21 A}=1.15$ \\
\hline \hline$w_{1} / w_{2}$ & 1.0000 & .9707 & 1.0000 & .9801 \\
$L_{1 A}$ & .5000 & .4221 & .3000 & .2275 \\
$L_{1 B}$ & .5000 & .5779 & .7000 & .7725 \\
$L_{2 A}$ & .5000 & .5757 & .3000 & .3711 \\
$L_{2 B}$ & .5000 & .4243 & .7000 & .6289 \\
\hline$\varphi_{12 A}^{*}$ & .3257 & .3206 & .3257 & .3273 \\
$\varphi_{11 A}^{*}$ & .2240 & .2250 & .2240 & .2238 \\
$\varphi_{12 B}^{*}$ & .3257 & .3092 & .3257 & .3144 \\
$\varphi_{11 B}^{*}$ & .2240 & .2274 & .2240 & .2262 \\
\hline$\varphi_{21 A}^{*}$ & .3257 & .3012 & .3257 & .2957 \\
$\varphi_{22 A}^{*}$ & .2240 & .2296 & .2240 & .2314 \\
$\varphi_{21 B}^{*}$ & .3257 & .3443 & .3257 & .3380 \\
$\varphi_{22 B}^{*}$ & .2240 & .2214 & .2240 & .2222 \\
\hline$\Phi_{1 A}^{R}$ & .5564 & .5590 & .5564 & .5556 \\
$\Phi_{1 B}^{R}$ & .5564 & .5651 & .5564 & .5623 \\
$\Phi_{2 A}^{R}$ & .5564 & .5694 & .5564 & .5724 \\
$\Phi_{2 B}^{R}$ & .5564 & .5476 & .5564 & .5505 \\
\hline$U_{1}$ & .1230 & .1242 & .1376 & .1385 \\
$U_{2}$ & .1230 & .1238 & .1376 & .1381 \\
\hline & & & & \\
\hline
\end{tabular}

Table 3: Effects of Trade Liberalization 
The first column of numbers in Table 3 shows the benchmark equilibrium (when $\alpha_{A}=.5$ and $\left.\tau_{21 A}=1.30\right)$. The second column shows what happens when country 1 unilaterally opens up to trade in industry $A$ ( $\tau_{21 A}$ is decreased from 1.30 to 1.15 holding $\tau_{21 B}=\tau_{12 A}=\tau_{12 B}=1.30$ fixed). This leads to productivity rising more strongly in the non-liberalized industry $B\left(\Phi_{1 B}^{R}\right.$ increases from .5564 to .5651$)$ than in the liberalized industry $A\left(\Phi_{1 A}^{R}\right.$ increases from .5564 to .5590$)$, consistent with Theorem 2. Since productivity rises in the liberalized industry, we are illustrating a case where the wage effect of trade liberalization dominates the competitiveness effect. The third and fourth columns show the effects of the same trade liberalization when industry $A$ is smaller $\left(\alpha_{A}=.3\right.$, all other parameter values unchanged). Then the wage effect of trade liberalization is smaller and is dominated by the competitiveness effect. Productivity in the liberalized industry decreases $\left(\Phi_{1 A}^{R}\right.$ decreases from .5564 to .5556$)$ and productivity in the non-liberalized industry increases $\left(\Phi_{1 B}^{R}\right.$ increases from .5564 to .5623), consistent with Theorem 4.

To see the intuition behind these results, consider the $\alpha_{A}=.3$ "small industry" case first and focus on what happens in industry $A$. When country 1 opens up to trade in industry $A$, country 2 firms earn higher profits from exporting. These higher export profits lead to more entry and greater industrial employment ( $L_{2 A}$, which is proportional to the mass of entrants and active firms, increases from .3000 to .3711 ). As the industry becomes more populated with firms, the country 2 demand for each individual firm's product decreases, so the least productive firms are forced to exit $\left(\varphi_{22 A}^{*}\right.$ increases from 2240 to .2314 ). Even though the increase in labor demand bids up the wage rate in country 2 ( $w_{1} / w_{2}$ decreases from 1.000 to .9801$)$, the wage increase is not large enough to completely offset the tariff reduction by country 1 and more country 2 firms become exporters $\left(\varphi_{21 A}^{*}\right.$ decreases from .3257 to .2957). Since expanding exporters are more productive than exiting non-exporters, productivity rises for country 2 in industry $A$ ( $\Phi_{2 A}^{R}$ increases from .5564 to .5724$)$. For firms in country 1, the picture is very different. Now they are competing against more productive firms in their export market, they earn lower profits from exporting and this sets into motion the opposite effects. Fewer country 1 firms become exporters ( $\varphi_{12 A}^{*}$ increases from .3257 to .3273 ), entry is discouraged and the mass of firms in the industry falls ( $L_{1 A}$ decreases from .3000 to 2275 ) until the expected profits from domestic sales increase to offset the loss of expected profits from exporting. The increase in domestic profits allows less productive firms to survive in the domestic market $\left(\varphi_{11 A}^{*}\right.$ decreases from .2240 to .2238$)$. Thus, 
we get a reallocation of resources from more productive to less productive firms in country 1 , lowering industry productivity ( $\Phi_{1 A}^{R}$ decreases from .5564 to .5556$)$.

Next, focus on what happens in industry $B$ when country 1 opens up to trade in industry $A$. Because wages rise in country $2\left(w_{1} / w_{2}\right.$ decreases from 1.000 to .9801$)$, it becomes less profitable for country 2 firms to export and there is a reallocation of resources from more productive to less produc-

tive firms, lowering productivity ( $\Phi_{2 B}^{R}$ decreases from .5564 to .5505$)$. Because wages fall in country $1\left(w_{1} / w_{2}\right.$ decreases from 1.000 to .9801$)$, there is a reallocation of resources from less productive to more productive firms, raising productivity $\left(\Phi_{1 B}^{R}\right.$ increases from .5564 to .5623$)$.

Finally, turn to the effects of trade liberalization when industry $A$ is larger $\left(\alpha_{A}=.5\right)$. We obtain the same qualitative effects in industry $B$ : because wages rise in country $2\left(w_{1} / w_{2}\right.$ decreases from 1.000 to .9707$)$, productivity falls $\left(\Phi_{2 B}^{R}\right.$ decreases from .5564 to .5476$)$ and because wages fall in country 1 $\left(w_{1} / w_{2}\right.$ decreases from 1.000 to .9707$)$, productivity rises $\left(\Phi_{1 B}^{R}\right.$ increases from .5564 to .5651$)$. But the qualitative effects are different for the industry $A$ that opens up to trade because there is a larger fall in country 1 wages. Even though trade liberalization raises productivity in country $2\left(\Phi_{2 A}^{R}\right.$ increases from .5564 to .5694 ), which by itself makes exporting less attractive for country 1 firms, the larger fall in country 1 wages now dominates and country 1 productivity in industry $A$ actually rises $\left(\Phi_{1 A}^{R}\right.$ increases from .5564 to .5590$)$.

Although the impact of trade liberalization on industrial productivity is the main focus of this paper, we also report the impact of trade liberalization on consumer welfare in the last two rows of Table 3. $U_{1}$ and $U_{2}$ denote the steady-state utility levels of the representative consumer in countries 1 and 2 , respectively. In the $\alpha_{A}=.5$ case, trade liberalization by country 1 raises consumer welfare in country $2\left(U_{2}\right.$ increases from .1230 to .1238$)$ and raises even more consumer welfare in country $1\left(U_{1}\right.$ increases from .1230 to .1242 ). Thus country 2 benefits when country 1 opens up to trade and country 1 benefits even more by unilaterally opening up to trade. Looking at the $\alpha_{A}=.3$ case, we obtain qualitatively similar welfare effects.

\section{Comparison with Trefler (2004)}

In this section, we compare predictions of the multi-industry Melitz model with a representative empirical study by Trefler (2004). We first explain how Trefler (2004) estimated the impact of the Canadian 
tariff cuts on Canadian industrial productivity. Then, we calibrate the Melitz model to fit Canada-US trade during this time period and simulate the impact of the Canadian tariff cuts. Finally, using the numbers from the numerical simulation and Trefler's formula, we calculate the impact of the Canadian tariff cuts implied by the calibrated Melitz model and compare the model's prediction with Trefler's estimate.

Trefler (2004) In 1989, Canada and the US started to reduce all tariffs on trade between the two countries as part of the Canada-US Free Trade Agreement (CUFTA). Trefler (2004) studied the effects of this FTA on Canadian industrial productivity from 1988 to 1996 by estimating the following equation:

$$
\Delta \ln \Phi_{s, t}^{C A}=\gamma_{s}+\gamma_{t}+\beta^{C A} \Delta \tau_{s, t}^{C A}+\beta^{U S} \Delta \tau_{s, t}^{U S}+\sum_{i} \beta_{i} \Delta Z_{i s, t}+\varepsilon_{s t} .
$$

Subscript $s$ denotes each of 213 manufacturing industries in Canada and subscript $t$ denotes two periods: pre-FTA (1980-86) and post-FTA (1988-96). The dependent variable $\Delta \ln \Phi_{s, t}^{C A}$ is the average annual log change of labor productivity for industry $s$ during period $t$. The first two covariates are industry-fixed effects and time fixed effects for the two periods, respectively. The two terms $\Delta \tau_{s, t}^{C A}$ and $\Delta \tau_{s, t}^{U S}$ are the average annual change of Canadian tariff concessions to the US and US tariff concessions to Canada for industry $s$ during period $t$, respectively. Concessions $\Delta \tau_{s, t}^{C A}$ and $\Delta \tau_{s, t}^{U S}$ are expressed as negative values: $\Delta \tau_{s, t}^{C A}<\Delta \tau_{s^{\prime}, t}^{C A}<0$ holds if Canada gives greater tariff concessions to the US for industry $s$ than for industry $s^{\prime}$. The estimated equation also includes other control variables $Z_{i s, t}$ for business cycle effects and industry-time-dependent shocks.

Trefler (2004) found a negative $\hat{\beta}^{C A}$ that is both statistically and economically significant. ${ }^{14}$ By multiplying estimated $\hat{\beta}^{C A}$ and Canadian average tariff cuts $\Delta \tau_{s, t}^{C A}$ for the most impacted importcompeting industries, which experienced more than 4 percentage point tariff cuts, Trefler estimated that the Canadian tariff cuts increased industrial productivity by $15 \%$ in the most impacted importcompeting industries. Furthermore, he estimated regressions of plant-level labor productivity on the same covariates in equation (27) and found statistically insignificant $\beta^{C A}$. This finding implies that industrial productivity rose in the liberalized industries not because individual firms improved produc-

\footnotetext{
${ }^{14}$ In the tables of his paper, Trefler (2004) reports the average of $\hat{\beta}^{C A} \Delta \tau_{s, t}^{C A}$ among the most liberalized industries instead of $\hat{\beta}^{C A}$ itself. Therefore, the positive numbers reported in the column $\beta^{C A}$ of Table 2 in Trefler (2004) are constructed from negative $\hat{\beta}^{C A}$ since $\Delta \tau_{s, t}^{C A}$ is also negative.
} 
tivity on average, but mainly because the sales share shifted from less productive to more productive firms within industries.

Calibration We calibrate the Melitz model to fit Canada-US trade during this time period. For the numerical results reported in Table 4, we relax the assumption of symmetric countries by assuming that country 1 (Canada) is ten times smaller than country 2 (US), that is, $L_{1}=0.1$ and $L_{2}=1$. The benchmark parameters $\sigma_{s}=3.8, \delta_{i s}=.025, b_{i s}=.2, \theta_{s}=4.582, F_{i s}=2, f_{i i s}=.043$ and $\alpha_{A}=.5$ are the same as before. We define trade costs as $\tau_{i j s}=1+t_{i j s}+s h i p$, where $t_{i j s}$ are policy-induced barriers (tariffs) and ship are the natural trade costs (shipping costs). Before the FTA went into effect, the average Canadian tariff rate against the US was 8 percent and the average US tariff rate against Canada was 4 percent (Trefler, 2004). To be consistent with the 8 percent average, we assume a 12 percent Canadian tariff rate in industry $A$ and a 4 percent Canadian tariff rate in industry $B$ in our 1988 benchmark equilibrium $\left(\tau_{21 A}=1.12+\right.$ ship and $\tau_{21 B}=1.04+$ ship $)$. We assume that the 4 percent US tariff rate applies to both industries in the 1988 benchmark equilibrium $\left(\tau_{12 A}=\tau_{12 B}=1.04+\right.$ ship $)$. Since the FTA eliminated all tariffs on trade between Canada and the US, we assume that the only trade costs are shipping costs in the 1996 benchmark equilibrium $\left(\tau_{12 A}=\tau_{12 B}=\tau_{21 A}=\tau_{21 B}=1+\right.$ ship $)$. Allowing the fixed costs of entering foreign markets to differ for Canadian and US firms, there are three benchmark parameters that still need to be chosen: $f_{12 s}, f_{21 s}$ and ship. We chose these three parameters to match two stylized facts about Canadian exports: 20 percent of Canadian firms export to the US (Baldwin and $\mathrm{Gu}, 2003$ ) and 56 percent of Canadian manufacturing value-added output is exported to the US (de Sousa, Mayer and Zignago, 2012). It turns out that these 2 stylized facts exactly hold in our 1996 benchmark equilibrium when $f_{12 s}=0.273, f_{21 s}=0.247$ and $\operatorname{ship}=.0494$. Thus we will assume that shipping costs are roughly 5 percent.

The first column of numbers in Table 4 shows the 1988 benchmark equilibrium where the Canadian tariff rates in industries $A$ and $B$ are $12 \%$ and $4 \%$, respectively $\left(\tau_{21 A}=1+.12+.05=1.17\right.$, $\left.\tau_{21 B}=1+.04+.05=1.09\right)$, and the US tariff rate is $4 \%$ in both industries $\left(\tau_{12 A}=\tau_{12 B}=\right.$ $1+.04+.05=1.09$ ). The second column shows what happens if Canada unilaterally opens up to trade by reducing its tariff rates (12\% and $4 \%)$ to zero while holding the US tariff rate (4\%) fixed. This represents a hypothetical calculation but it is precisely what Trefler (2004) studies in his empirical 


\begin{tabular}{|c|c|c|c|}
\hline & $\begin{array}{c}1988 \\
\text { Benchmark }\end{array}$ & $\begin{array}{c}\text { Only Canada } \\
\text { Liberalizes }\end{array}$ & $\begin{array}{c}1996 \\
\text { Benchmark }\end{array}$ \\
\hline & $\tau_{21 A}=1.17$ & $\tau_{21 A}=1.05$ & $\tau_{21 A}=1.05$ \\
\hline & $\tau_{21 B}=1.09$ & $\tau_{21 B}=1.05$ & $\tau_{21 B}=1.05$ \\
\hline & $\tau_{12 A}=1.09$ & $\tau_{12 A}=1.09$ & $\tau_{12 A}=1.05$ \\
\hline & $\tau_{12 B}=1.09$ & $\tau_{12 B}=1.09$ & $\tau_{12 B}=1.05$ \\
\hline$w_{1} / w_{2}$ & .8687 & .8529 & .8698 \\
\hline$L_{1 A}$ & .0587 & .0500 & .0500 \\
\hline$L_{1 B}$ & .0413 & .0500 & .0500 \\
\hline$L_{2 A}$ & .4924 & .5000 & .5000 \\
\hline$L_{2 B}$ & .5076 & .5000 & .5000 \\
\hline$\varphi_{12 A}^{*}$ & .3748 & .3665 & .3628 \\
\hline$\varphi_{11 A}^{*}$ & .2466 & .2524 & .2555 \\
\hline$\varphi_{12 B}^{*}$ & .3760 & .3665 & .3628 \\
\hline$\varphi_{11 B}^{*}$ & .2459 & .2524 & .2555 \\
\hline$\varphi_{21 A}^{*}$ & .6518 & .6137 & .6049 \\
\hline$\varphi_{22 A}^{*}$ & .2152 & .2158 & .2159 \\
\hline$\varphi_{21 B}^{*}$ & .6054 & .6137 & .6049 \\
\hline$\varphi_{22 B}^{*}$ & .2159 & .2158 & .2159 \\
\hline$\Phi_{1 A}^{R}$ & .7029 & .7142 & .7192 \\
\hline$\Phi_{1 B}^{R}$ & .7013 & .7142 & .7192 \\
\hline$\Phi_{2 A}^{R}$ & .5249 & .5330 & .5352 \\
\hline$\Phi_{2 B}^{R}$ & .5351 & .5330 & .5352 \\
\hline$U_{1}$ & .0594 & .0609 & .0617 \\
\hline$U_{2}$ & .1184 & .1185 & .1186 \\
\hline
\end{tabular}

Table 4: The Case of Canada-US Trade 
work. Notice that when Canada unilaterally opens up to trade, there is a larger tariff decrease in industry $A(12 \%$ drops to $0 \%)$ than in industry $B(4 \%$ drops to $0 \%)$. In his empirical work, Trefler focuses on what happens to industrial productivity in the Canadian industries that experienced the largest tariff decreases, holding the US tariff rates fixed. The third column shows the 1996 benchmark equilibrium where the FTA has been put into effect and all tariff rates on trade between Canada and the US equal zero $\left(\tau_{21 A}=\tau_{21 B}=\tau_{12 A}=\tau_{12 B}=1+0+.05=1.05\right)$.

The effects of unilateral trade liberalization shown in Table 4 are qualitatively the same as those shown in Table 3 and the intuition for these effects is the same, so we will be brief in discussing the Table 4 results. The important thing to notice is that unilateral trade liberalization by Canada raises productivity by 1.6 percent in the industry $A$ with the larger tariff decrease $\left(\Phi_{1 A}^{R}\right.$ increases from .7029 to .7142$)$ and raises productivity by 1.8 percent in the industry $B$ with the smaller tariff decrease $\left(\Phi_{1 B}^{R}\right.$ increases from .7013 to .7142). Thus, there is a bigger percentage increase in productivity in the Canadian industry with the smaller tariff decrease and our Theorem 2 results continue to hold in the case of a small country opening up to trade with a much bigger country. The difference in percentage increases is small $(1.6 \%-1.8 \%=-0.2 \%)$ because the competitiveness effect is small when a small country opens up to trade with a much bigger country. But what is important is that it exists.

Comparison Now we are ready to compare what Trefler (2004) finds empirically with what the calibrated Melitz model predicts. Among the many findings reported in Trefler (2004), we focus on the main finding: that the Canadian tariff cuts increased productivity of the most impacted importcompeting industries by $15 \%$. This number is widely cited in survey papers and textbooks. We simply ask whether the calibrated model predicts this $15 \%$ increase if the corresponding number is calculated as Trefler did.

We interpret industry $A$ as representing the most impacted import competing industries in Trefler's analysis and calculate the effect of Canadian tariff cuts on the productivity of industry $A$. Though the calibrated model predicts that the Canadian unilateral tariff cuts lead to a $1.6 \%$ productivity increase for industry $A$ (in column 2 of Table 4), this number is not comparable to Trefler's calculation (15\%) because his calculation does not include time fixed effects $\gamma_{t}$ that capture common effects for all industries. In the following, we consider what equation (27) would estimate for $\hat{\beta}^{C A}$ based on the numbers in column 2 of Table 4, and then calculate $\hat{\beta}^{C A} \Delta \tau_{A, t}^{C A}$ as Trefler did. 
When the numbers in column 2 of Table 4 are obtained, industries are treated symmetrically and the US tariffs do not change. By substituting no industry difference $\left(\gamma_{s}=\Delta Z_{i s, t}=0\right)$ and no US tariff change $\left(\Delta \tau_{s, t}^{U S}=0\right)$, equation (27) becomes $\Delta \ln \Phi_{s, t}^{C A}=\gamma_{t}+\beta^{C A} \Delta \tau_{s, t}^{C A}$. Then, the coefficient $\hat{\beta}^{C A}$ of Canadian tariff cuts is obtained by taking differences $\Delta \ln \Phi_{A, t}^{C A}-\Delta \ln \Phi_{B, t}^{C A}=$ $\hat{\beta}^{C A}\left[\Delta \tau_{A, t}^{C A}-\Delta \tau_{B, t}^{C A}\right]$ and yields

$$
\hat{\beta}^{C A}=\frac{\Delta \ln \Phi_{A, t}^{C A}-\Delta \ln \Phi_{B, t}^{C A}}{\Delta \tau_{A, t}^{C A}-\Delta \tau_{B, t}^{C A}}=\frac{0.016-0.018}{-0.12-(-0.04)}=0.025
$$

so the effect of Canadian tariff cuts on industry $A$ productivity is $\hat{\beta}^{C A} \Delta \tau_{A, t}^{C A}=(0.025)(-0.12)=$ -0.003. Therefore, according to Trefler's formula, the calibrated Melitz model predicts that the Canadian tariff cuts decrease productivity in the most impacted import competing industries by $0.3 \%$.

Clearly, there is a big difference between what Trefler finds empirically $(+15 \%)$ and what the Melitz model implies (-0.3\%). We conclude that what Trefler finds empirically is evidence against the Melitz model.

\section{Conclusion}

In order to establish that trade liberalization improves industrial productivity through within-industry resource reallocation, the empirical literature and the theoretical literature have taken different approaches. On the one hand, empirical studies have typically investigated episodes of unilateral and non-uniform liberalization in order to utilize the cross-industry variations in trade liberalization. On the other hand, theoretical studies have typically analyzed multilateral and uniform liberalization in models with a single representative industry.

We have demonstrated that this apparently small difference in approach between theoretical and empirical studies is not innocuous. Once the Melitz (2003) model is extended to analyze unilateral and non-uniform trade liberalization, it does not predict what researchers find empirically, that industrial productivity increases more strongly in liberalized industries than in non-liberalized industries. Instead, we find that industrial productivity increases more strongly in non-liberalized industries than in liberalized industries. When one country opens up to trade in one industry, we find that productivity 
falls if the industry is sufficiently small. If the industry is larger, so productivity rises, we find that it rises even more in the industries that did not open up to trade. So, if we take the Melitz model seriously when looking at the real world, other things being equal, we should observe that productivity is high in industries with high tariffs and low in industries with low tariffs. This is the central prediction of the Melitz (2003) model that should be confirmed by cross industry regressions.

\section{References}

[1] Baggs, Jen (2005) "Firm survival and exit in response to trade liberalization." Canadian Journal of Economics, 38(4), 1364-1383.

[2] Baldwin, John R., and Wulong Gu (2003) "Export-market participation and productivity performance in Canadian manufacturing." Canadian Journal of Economics, 36(3), 634-657.

[3] Balistreri, Edward J., Russell H. Hillberry, and Thomas F. Rutherford (2011) "Structural estimation and solution of international trade models with heterogeneous firms." Journal of International Economics, 83, 95-108.

[4] Bernard, Andrew B., J. Bradford Jensen, Stephen J. Redding, and Peter K. Schott (2007) "Firms in International Trade.” Journal of Economic Perspectives, 21(3), 105-130.

[5] Bernard, Andrew B., J. Bradford Jensen, Stephen J. Redding, and Peter K. Schott (2012) "The Empirics of Firm Heterogeneity and International Trade.” Annual Review of Economics, 4, 283313

[6] Bernard, Andrew B., Stephen J. Redding, and Peter K. Schott (2007) "Comparative Advantage and Heterogeneous Firms.” Review of Economic Studies, 74 (1), 31-66.

[7] Demidova, Svetlana (2008), "Productivity Improvements and Falling Trade Costs: Boon or Bane?" International Economic Review, 49(4), 1437-1462.

[8] Demidova, Svetlana and Andres Rodriguez-Clare (2009) "Trade Policy under Firm-Level Heterogeneity in a Small Economy." Journal of International Economics, 78(1), 100-112. 
[9] Demidova, Svetlana and Andres Rodriguez-Clare (2013) "The Simple Analytics of the Melitz Model in a Small Economy.” Journal of International Economics, 90(2), 266-272.

[10] de Sousa, Jose, Thierry Mayer, and Soledad Zignago (2012) "Market access in global and regional trade." Regional Science and Urban Economics, 42(6), 1037-1052.

[11] Eslava, Marcela, John Haltiwanger, Adriana Kugler, and Maurice Kugler (2013) "Trade and Market Selection: Evidence from Manufacturing Plants in Colombia.” Review of Economic Dynamics, $16,135-158$.

[12] Felbermayr, Gabriel, Benjamin Jung, and Mario Larch (2013) "Optimal tariffs, retaliation, and the welfare loss from tariff wars in the Melitz model.” Journal of International Economics, , 89(1), $13-25$

[13] Fernandes, Ana M. (2007) "Trade policy, trade volumes and plant-level productivity in Colombian manufacturing industries.” Journal of International Economics, 71(1), 52-71.

[14] Harrison, Ann E., Leslie A. Martin, and Shanthi Nataraj (2013) "Learning Versus Stealing: How Important are Market-Share Reallocations to India's Productivity Growth?" forthcoming in World Bank Economic Review.

[15] Head, Keith and John Ries (1999) "Rationalization effects of tariff reductions." Journal of International Economics, 47(2), 295-320.

[16] Helpman, Elhanan (2011) Understanding Global Trade. Harvard University Press, Cambridge, Massachusetts.

[17] Hopenhayn, Hugo A. (1992) “Entry, Exit, and Firm Dynamics in Long Run Equilibrium.” Econometrica, 60(5), 1127-50.

[18] Krugman, Paul (1979) "Increasing Returns, Monopolistic Competition, and International Trade." Journal of International Economics, 9(4), 469-79.

[19] Krugman, Paul (1980) “Scale Economy, Product Differentiation, and the Pattern of Trade." American Economic Review, 70(5), 950-59. 
[20] Lileeva, Alla (2008) "Trade liberalization and productivity dynamics: evidence from Canada." Canadian Journal of Economics, 41(2), 360-390.

[21] Melitz, Marc J. (2003) "The Impact of Trade on Intra-Industry Reallocations and Aggregate Industry Productivity." Econometrica, 71(6), 1695-1725.

[22] Melitz, Marc J. and G.I.P. Ottaviano (2008) “Market Size, Trade and Productivity.” Review of Economic Studies, 75 (1), 295-316.

[23] Melitz, Marc J. and Stephen J. Redding (2012) “Heterogeneous Firms and Trade.” NBER Working Paper No. 18652.

[24] Melitz, Marc J. and Daniel Trefler (2012) “Gains form Trade when Firms Matter." Journal of Economic Perspectives, 26(2), 91-118.

[25] Nataraj, Shanthi (2011) “The impact of trade liberalization on productivity: Evidence from India's formal and informal manufacturing sectors.” Journal of International Economics, 85(2), 292-301.

[26] Okubo, Toshihiro (2009) "Firm heterogeneity and Ricardian comparative advantage within and across sectors." Economic Theory, 38(3), 533-559.

[27] Olley, C. Steven, and Ariel Pakes (1996) "The dynamics of productivity in the telecommunications equipment industry." Econometrica, 64(6), 1263-1297.

[28] Pavcnik, Nina (2002) “Trade Liberalization, Exit, and Productivity Improvement: Evidence from Chilean Plants." Review of Economic Studies, 69(1), 245-76

[29] Redding, Stephen J. (2011) “Theories of Hetrogeneous Firms and Trade." Annual Review of Economics, 3, 77-105.

[30] Sivadasan, Jagadeesh. (2009) "Barriers to Competition and Productivity: Evidence from India." The BE Journal of Economic Analysis \& Policy, 9(1), 1935-1682.

[31] Trefler, Daniel (2004) “The Long and Short of the Canada-U.S. Free Trade Agreement.” American Economic Review, 94(4), 870-895. 
[32] Tybout, James R. (2003) “Plant- and Firm-Level Evidence on "New” Trade Theories.” in E. Kwan Choi and James Harrigan eds. Handbood of International Trade, 388-415. Blackwell Publishing, Oxford.

[33] Tybout, James R. and M. Daniel Westbrook (1995) “Trade Liberalization and the Dimensions of Efficiency Change in Mexican Manufacturing Industries.” Journal of International Economics, 39(1), 53-78. 


\section{Appendix: Proofs}

There is also an Online Appendix available from our website where we present all calcurations.

\section{Proof for Lemma 1}

Equation (17) defines $M_{1 s e}$ as a function of $w_{1}, \tau_{12 s}$ and $\tau_{21 s}$, and can be written in function form as $M_{1 s e}\left(w_{1}, \tau_{12 s}, \tau_{21 s}\right)$. To determine the properties of this function, we calculate the partial derivatives.

Given $\theta_{s}>\sigma_{s}-1=\rho_{s} \sigma_{s}>\rho_{s}$, we obtain $\frac{\partial \phi_{12 s}}{\partial w_{1}}<0, \frac{\partial \phi_{12 s}}{\partial \tau_{12 s}}<0, \frac{\partial \phi_{21 s}}{\partial w_{1}}>0, \frac{\partial \phi_{21 s}}{\partial \tau_{21 s}}<0$, and it follows that

$$
\begin{aligned}
\frac{\partial M_{1 s e}}{\partial w_{1}}= & \alpha_{s}\left[\frac{\left(w_{1} X_{1 s}-\phi_{12 s} X_{2 s}\right) L_{1}-w_{1} L_{1}\left(X_{1 s}-\frac{\partial \phi_{12 s}}{\partial w_{1}} X_{2 s}\right)}{\left(w_{1} X_{1 s}-\phi_{12 s} X_{2 s}\right)^{2}}\right. \\
\left.-\frac{\left(X_{2 s}-\phi_{21 s} w_{1} X_{1 s}\right) \frac{\partial \phi_{21 s}}{\partial w_{1}} L_{2}+\phi_{21 s} L_{2}\left(\phi_{21 s}+\frac{\partial \phi_{21 s}}{\partial w_{1}} w_{1}\right) X_{1 s}}{\left(X_{2 s}-\phi_{21 s} w_{1} X_{1 s}\right)^{2}}\right] & \alpha_{s}\left[\frac{-\phi_{12 s} X_{2 s} L_{1}+w_{1} L_{1} \frac{\partial \phi_{12 s}}{\partial w_{1}} X_{2 s}}{\left(w_{1} X_{1 s}-\phi_{12 s} X_{2 s}\right)^{2}}-\frac{X_{2 s} \frac{\partial \phi_{21 s}}{\partial w_{1}} L_{2}+\left(\phi_{21 s}\right)^{2} L_{2} X_{1 s}}{\left(X_{2 s}-\phi_{21 s} w_{1} X_{1 s}\right)^{2}}\right]<0 \\
\frac{\partial M_{1 s e}}{\partial \tau_{12 s}} & =\alpha_{s}\left[\frac{\left(w_{1} X_{1 s}-\phi_{12 s} X_{2 s}\right) 0+w_{1} L_{1} \frac{\partial \phi_{12 s}}{\partial \tau_{12 s}} X_{2 s}}{\left(w_{1} X_{1 s}-\phi_{12 s} X_{2 s}\right)^{2}}-0\right] \\
& =\alpha_{s}\left[\frac{w_{1} L_{1} \frac{\partial \phi_{12 s}}{\partial \tau_{12 s} X_{2 s}}}{\left(w_{1} X_{1 s}-\phi_{12 s} X_{2 s}\right)^{2}}\right]<0 \\
\frac{\partial M_{1 s e}}{\partial \tau_{21 s}} & =\alpha_{s}\left[0-\frac{\left(X_{2 s}-\phi_{21 s} w_{1} X_{1 s}\right) \frac{\partial \phi_{21 s}}{\partial \tau_{21 s}} L_{2}+\phi_{21 s} L_{2} \frac{\partial \phi_{21 s}}{\partial \tau_{21 s}} w_{1} X_{1 s}}{\left(X_{2 s}-\phi_{21 s} w_{1} X_{1 s}\right)^{2}}\right] \\
& =-\alpha_{s}\left[\frac{X_{2 s} \frac{\partial \phi_{21 s}}{\partial \tau_{21 s}} L_{2}}{\left(X_{2 s}-\phi_{21 s} w_{1} X_{1 s}\right)^{2}}\right]>0 .
\end{aligned}
$$

Thus, the function $M_{1 s e}\left(w_{1}, \tau_{12 s}, \tau_{21 s}\right)$ has the properties $\frac{\partial M_{1 s e}}{\partial w_{1}}<0, \frac{\partial M_{1 s e}}{\partial \tau_{12 s}}<0$ and $\frac{\partial M_{1 s e}}{\partial \tau_{21 s}}>0$.

\section{Proof for Lemma 2}

Equation (19) shows the export productivity cut-off $\varphi_{12 s}^{*}$ for country 1 in sector $s$ as a function of the country 1 wage rate $w_{1}$ and trade costs $\tau_{12 s}$ and $\tau_{21 s}$. To determine the partial derivative of this function with respect to $w_{1}$, note that

$$
\phi_{12 s} \phi_{21 s}=\frac{1}{\left(\tau_{12 s} \tau_{21 s}\right)^{\theta_{s}}}\left(\frac{f_{11 s} f_{22 s}}{f_{12 s} f_{21 s}}\right)^{\left(\theta_{s}-\sigma_{s}+1\right) /\left(\sigma_{s}-1\right)}
$$


does not depend on $w_{1}$ and

$$
\frac{\phi_{12 s}}{w_{1}}=\left[\frac{\delta_{2 s} f_{12 s}}{\delta_{1 s} f_{22 s}}\left(\frac{b_{1 s}}{b_{2 s}}\right)^{\theta_{s}} T_{12 s}^{-\theta_{s}} w_{1}^{1-\theta_{s} / \rho_{s}}\right] w_{1}^{-1}=\left[\frac{\delta_{2 s} f_{12 s}}{\delta_{1 s} f_{22 s}}\left(\frac{b_{1 s}}{b_{2 s}}\right)^{\theta_{s}} T_{12 s}^{-\theta_{s}}\right] w_{1}^{-\theta_{s} / \rho_{s}}
$$

is decreasing in $w_{1}$. Thus the export productivity cut-off $\varphi_{12 s}^{*}$ is an unambiguously increasing function of $w_{1}$ and $\frac{\partial \varphi_{12 s}^{*}}{\partial w_{1}}>0$.

To determine the partial derivative of $\varphi_{12 s}^{*}$ with respect to $\tau_{12 s}$, note that both $\phi_{12 s} \phi_{21 s}$ and $\frac{\phi_{12 s}}{w_{1}}$ are proportional to $\tau_{12 s}^{-\theta_{s}}$. It follows from (19) that an increase in $\tau_{12 s}$ causes the numerator $\gamma_{1 s} f_{12 s}(1-$ $\left.\phi_{12 s} \phi_{21 s}\right)$ to increase and the denominator $F_{2 s}\left(\phi_{12 s} / w_{1}\right)-\phi_{12 s} \phi_{21 s} F_{1 s}$ to decrease, so $\frac{\partial \varphi_{12}^{*}}{\partial \tau_{12 s}}>0$.

To determine the partial derivative of $\varphi_{12 s}^{*}$ with respect to $\tau_{21 s}$ takes more work. We consider how the competitiveness curve shifts for a given $\varphi_{12 s}^{*}$ when $\tau_{21 s}$ decreases. When $\tau_{21 s}$ decreases holding all other parameter values fixed and holding $\varphi_{12 s}^{*}$ fixed, the free entry condition (11) for country 1 , $f_{11 s} \varphi_{11 s}^{*-\theta_{s}}+f_{12 s} \varphi_{12 s}^{*-\theta_{s}}=F_{1 s} / \gamma_{1 s}$ implies that $\varphi_{11 s}^{*}$ remains fixed. The other free entry condition for country $2, f_{21 s} \varphi_{21 s}^{*-\theta_{s}}+f_{22 s} \varphi_{22 s}^{*-\theta_{s}}=F_{2 s} / \gamma_{2 s}$ implies that $\varphi_{21 s}^{*}$ and $\varphi_{22 s}^{*}$ move in opposite directions. From (7), the cut-off productivity levels satisfy $\varphi_{12 s}^{*} \varphi_{21 s}^{*}=\left(T_{12 s} w_{1}^{1 / \rho_{s}} \varphi_{22 s}^{*}\right)\left(T_{21 s} w_{1}^{-1 / \rho_{s}} \varphi_{11 s}^{*}\right)=$ $T_{12 s} \varphi_{22 s}^{*} T_{21 s} \varphi_{11 s}^{*}$. Because $\varphi_{12 s}^{*}$ is fixed, $T_{12 s}$ is fixed, $T_{21 s}$ decreases and $\varphi_{11 s}^{*}$ is fixed, $\varphi_{21 s}^{*}$ and $\varphi_{22 s}^{*}$ can move in opposite directions only when $\varphi_{22 s}^{*}$ increases and $\varphi_{21 s}^{*}$ decreases. Thus, a decrease in $\tau_{21 s}$ holding $\varphi_{12 s}^{*}$ fixed leads to $\varphi_{11 s}^{*}$ remaining fixed, $\varphi_{22 s}^{*}$ increasing and $\varphi_{21 s}^{*}$ decreasing. But then the cut-off productivity condition (7) $\varphi_{12 s}^{*}=T_{12 s} w_{1}^{1 / \rho_{s}} \varphi_{22 s}^{*}$ implies that $w_{1}$ must decrease. It follows that when $\tau_{21 s}$ decreases holding $\varphi_{12 s}^{*}$ fixed, then the wage rate $w_{1}$ must decrease and the competitiveness curve shifts down. This is equivalent to the competitiveness curve shifting out (as illustrated in Figure 3), so $\frac{\partial \varphi_{12 s}^{*}}{\partial \tau_{21 s}}<0$.

\section{Proof of Lemma 3}

(Part 1) One measure of industrial productivity $\Phi_{1 s}^{R}$ is the industrial average of firm productivity $\varphi$ weighted by each firm's revenue share in the industry and is given by

$$
\Phi_{1 s}^{R} \equiv \int_{0}^{\infty} \varphi v_{1 s}(\varphi) d \varphi \quad \text { where } \quad v_{1 s}(\varphi) \equiv \frac{\sum_{j=1,2} I\left(\varphi \geq \varphi_{1 j s}^{*}\right) r_{1 j s}(\varphi) M_{1 s} \mu_{1 s}(\varphi)}{\sum_{k=1,2} R_{1 k s}} .
$$


The function $v_{1 s}(\varphi)$ is a revenue-weighted density function for $\varphi$ since

$$
\begin{aligned}
\int_{0}^{\infty} v_{1 s}(\varphi) d \varphi & =\int_{0}^{\infty} \frac{\sum_{j=1,2} I\left(\varphi \geq \varphi_{1 j s}^{*}\right) r_{1 j s}(\varphi) M_{1 s} \mu_{1 s}(\varphi)}{\sum_{k=1,2} R_{1 k s}} d \varphi \\
& =\frac{1}{\sum_{k=1,2} R_{1 k s}} \sum_{j=1,2} \int_{\varphi_{1 j s}^{*}}^{\infty} r_{1 j s}(\varphi) M_{1 s} \mu_{1 s}(\varphi) d \varphi \\
& =\frac{1}{\sum_{k=1,2} R_{1 k s}} \sum_{j=1,2} R_{1 j s} \\
& =1 .
\end{aligned}
$$

To better understand the properties of $\Phi_{1 s}^{R}$, define $v_{1 j s}(\varphi) \equiv r_{1 j s}(\varphi) M_{1 s} \mu_{1 s}(\varphi) /\left(\sum_{k=1,2} R_{1 k s}\right)$. Then $v_{1 s}(\varphi)=\sum_{j=1,2} I\left(\varphi \geq \varphi_{1 j s}^{*}\right) v_{1 j s}(\varphi)$ and

$$
\begin{aligned}
\Phi_{1 s}^{R} & =\int_{0}^{\infty} \varphi v_{1 s}(\varphi) d \varphi \\
& =\int_{0}^{\infty} \varphi \sum_{j=1,2} I\left(\varphi \geq \varphi_{1 j s}^{*}\right) v_{1 j s}(\varphi) d \varphi \\
& =\int_{\varphi_{11 s}^{*}}^{\infty} \varphi v_{11 s}(\varphi) d \varphi+\int_{\varphi_{12 s}^{*}}^{\infty} \varphi v_{12 s}(\varphi) d \varphi \\
& =\int_{\varphi_{12 s}^{*}}^{\infty} \varphi\left[v_{11 s}(\varphi)+v_{12 s}(\varphi)\right] d \varphi+\int_{\varphi_{11 s}^{*}}^{\varphi_{12 s}^{*}} \varphi v_{11 s}(\varphi) d \varphi
\end{aligned}
$$

We know that $\sum_{k=1,2} R_{1 k s}=w_{1} M_{1 s e} X_{1 s}$ from (13), $M_{1 s} \mu_{1 s}(\varphi)=M_{1 s e} g_{1 s}(\varphi) / \delta_{1 s}$ and $r_{1 j s}(\varphi)=$ $\sigma_{s} w_{1} f_{1 j s}\left(\frac{\varphi}{\varphi_{1 j s}^{*}}\right)^{\sigma_{s}-1}$. It follows that

$$
\begin{aligned}
v_{1 j s}(\varphi) & =\frac{r_{1 j s}(\varphi) M_{1 s} \mu_{1 s}(\varphi)}{\sum_{k=1,2} R_{1 k s}} \\
& =\frac{r_{1 j s}(\varphi) M_{1 s e} g_{1 s}(\varphi) / \delta_{1 s}}{w_{1} M_{1 s e} X_{1 s}} \\
& =\frac{r_{1 j s}(\varphi)}{w_{1} X_{1 s}} \frac{g_{1 s}(\varphi)}{\delta_{1 s}} \\
& =\frac{\sigma_{s} f_{1 j s}}{X_{1 s}}\left(\frac{\varphi}{\varphi_{1 j s}^{*}}\right)^{\sigma_{s}-1} \frac{g_{1 s}(\varphi)}{\delta_{1 s}} .
\end{aligned}
$$

Therefore, productivity $\Phi_{1 s}^{R}$ can be written as a function of the domestic productivity cutoff $\varphi_{11 s}^{*}$ and the export productivity cutoff $\varphi_{12 s}^{*}$. Furthermore, the free entry condition

$$
\frac{f_{11 s}}{\left(\varphi_{11 s}^{*}\right)^{\theta_{s}}}+\frac{f_{12 s}}{\left(\varphi_{12 s}^{*}\right)^{\theta_{s}}}=\frac{F_{1 s}}{\gamma_{1 s}}
$$


determines $\varphi_{11 s}^{*}$ as an implicit function of $\varphi_{12 s}^{*}$ and we can solve for its derivative by totally differentiating. This yields $-f_{11 s} \theta_{s} \varphi_{11 s}^{*-\theta_{s}-1} d \varphi_{11 s}^{*}-f_{12 s} \theta_{s} \varphi_{12 s}^{*-\theta_{s}-1} d \varphi_{12 s}^{*}=0$ and rearranging terms, we obtain the derivative

$$
\frac{d \varphi_{11 s}^{*}}{d \varphi_{12 s}^{*}}=-\frac{f_{12 s}}{f_{11 s}}\left(\frac{\varphi_{11 s}^{*}}{\varphi_{12 s}^{*}}\right)^{\theta_{s}+1}<0 .
$$

Because (A.10) and (A.11) do not include the wage $w_{1}$ or variable trade costs, it is possible to write $\Phi_{1 s}^{R}$ as a function of $\varphi_{12 s}^{*}$ that does not include the wage $w_{1}$ or variable trade costs.

Taking the derivative of this function using Leibniz's Formula, we obtain

$$
\begin{aligned}
\frac{d \Phi_{1 s}^{R}}{d \varphi_{12 s}^{*}}= & \int_{\varphi_{12 s}^{*}}^{\infty} \varphi\left[\frac{d\left(v_{11 s}(\varphi)+v_{12 s}(\varphi)\right)}{d \varphi_{12 s}^{*}}\right] d \varphi-\varphi_{12 s}^{*}\left[v_{11 s}\left(\varphi_{12 s}^{*}\right)+v_{12 s}\left(\varphi_{12 s}^{*}\right)\right]+\varphi_{12 s}^{*} v_{11 s}\left(\varphi_{12 s}^{*}\right) \\
& +\int_{\varphi_{11 s}^{*}}^{\varphi_{12 s}^{*}} \varphi\left(\frac{d v_{11 s}(\varphi)}{d \varphi_{12 s}^{*}}\right) d \varphi-\varphi_{11 s}^{*} v_{11 s}\left(\varphi_{11 s}^{*}\right) \frac{d \varphi_{11 s}^{*}}{d \varphi_{12 s}^{*}} \\
= & \int_{\varphi_{12 s}^{*}}^{\infty} \varphi\left[\frac{d\left(v_{11 s}(\varphi)+v_{12 s}(\varphi)\right)}{d \varphi_{12 s}^{*}}\right] d \varphi-\varphi_{12 s}^{*} v_{12 s}\left(\varphi_{12 s}^{*}\right) \\
& +\int_{\varphi_{11 s}^{*}}^{\varphi_{12 s}^{*}} \varphi\left(\frac{d v_{11 s}(\varphi)}{d \varphi_{12 s}^{*}}\right) d \varphi-\varphi_{11 s}^{*} v_{11 s}\left(\varphi_{11 s}^{*}\right) \frac{d \varphi_{11 s}^{*}}{d \varphi_{12 s}^{*}}
\end{aligned}
$$

Thinking about the implications of a marginal decrease in $\varphi_{12 s}^{*}$, the four components of $d \Phi_{1 s}^{R} / d \varphi_{12 s}^{*}$ represent the change in industrial productivity associated with existing exporters, new exporters, remaining non-exporters and exiting firms.

To determine the sign of $d \Phi_{1 s}^{R} / d \varphi_{12 s}^{*}$, we first calculate the derivatives inside the integrals. From (A.10), the derivatives of $v_{11 s}(\varphi)$ and $v_{12 s}(\varphi)$ are

$$
\frac{d v_{1 j s}(\varphi)}{d \varphi_{1 j s}^{*}}=-\frac{\sigma_{s}\left(\sigma_{s}-1\right) \varphi^{\sigma_{s}-1} g_{1 s}(\varphi)}{X_{1 s} \delta_{1 s}} \frac{f_{1 j s}}{\left(\varphi_{1 j s}^{*}\right)^{\sigma_{s}}} \text { for } j=1,2
$$

It follows that

$$
\begin{aligned}
\frac{d\left(v_{11 s}(\varphi)+v_{12 s}(\varphi)\right)}{d \varphi_{12 s}^{*}} & =-\frac{\sigma_{s}\left(\sigma_{s}-1\right) \varphi^{\sigma_{s}-1} g_{1 s}(\varphi)}{X_{1 s} \delta_{1 s}}\left[\frac{f_{11 s}}{\left(\varphi_{11 s}^{*}\right)^{\sigma_{s}}} \frac{d \varphi_{11 s}^{*}}{d \varphi_{12 s}^{*}}+\frac{f_{12 s}}{\left(\varphi_{12 s}^{*}\right)^{\sigma_{s}}}\right] \\
& =-\frac{\sigma_{s}\left(\sigma_{s}-1\right) \varphi^{\sigma_{s}-1} g_{1 s}(\varphi)}{X_{1 s} \delta_{1 s}}\left[-\frac{f_{11 s}}{\left(\varphi_{11 s}^{*}\right)^{\sigma_{s}}} \frac{f_{12 s}}{f_{11 s}}\left(\frac{\varphi_{11 s}^{*}}{\varphi_{12 s}^{*}}\right)^{\theta_{s}+1}+\frac{f_{12 s}}{\left(\varphi_{12 s}^{*}\right)^{\sigma_{s}}}\right] \\
& =-\frac{\sigma_{s}\left(\sigma_{s}-1\right) \varphi^{\sigma_{s}-1} g_{1 s}(\varphi) f_{12 s}}{X_{1 s} \delta_{1 s}\left(\varphi_{12 s}^{*}\right)^{\sigma_{s}}}\left[1-\left(\frac{\varphi_{11 s}^{*}}{\varphi_{12 s}^{*}}\right)^{\theta_{s}-\sigma_{s}+1}\right]<0
\end{aligned}
$$


and

$$
\begin{aligned}
\frac{d v_{11 s}(\varphi)}{d \varphi_{12 s}^{*}} & =\frac{d v_{11 s}(\varphi)}{d \varphi_{11 s}^{*}} \frac{d \varphi_{11 s}^{*}}{d \varphi_{12 s}^{*}} \\
& =\frac{\sigma_{s}\left(\sigma_{s}-1\right) \varphi^{\sigma_{s}-1} g_{1 s}(\varphi)}{X_{1 s} \delta_{1 s}} \frac{f_{11 s}}{\left(\varphi_{11 s}^{*}\right)^{\sigma_{s}}} \frac{f_{12 s}}{f_{11 s}}\left(\frac{\varphi_{11 s}^{*}}{\varphi_{12 s}^{*}}\right)^{\theta_{s}+1} \\
& =\frac{\sigma_{s}\left(\sigma_{s}-1\right) \varphi^{\sigma_{s}-1} g_{1 s}(\varphi) f_{12 s}\left(\varphi_{11 s}^{*}\right)^{\theta_{s}-\sigma_{s}+1}}{X_{1 s} \delta_{1 s}\left(\varphi_{12 s}^{*}\right)^{\theta_{s}+1}}>0 .
\end{aligned}
$$

As a second step in determining the sign of $d \Phi_{1 s}^{R} / d \varphi_{12 s}^{*}$, we look at the change in industrial productivity associated with existing exporters and remaining non-exporters. To make progress, we first multiply both sides of the free entry condition (10) by $\sigma_{s} / w_{1} X_{1 s}$ and then use (A.10) to obtain

$$
\begin{array}{rr}
\frac{\sigma_{s}}{w_{1} X_{1 s}}\left[\frac{1}{\delta_{1 s}} \sum_{j=1,2} \int_{\varphi_{1 j s}^{*}}^{\infty}\left(\frac{r_{1 j s}(\varphi)}{\sigma_{s}}-w_{1} f_{1 j s}\right) g_{1 s}(\varphi) d \varphi\right] & =\frac{\sigma_{s}}{w_{1} X_{1 s}}\left[w_{1} F_{1 s}\right] \\
\sum_{j=1,2} \int_{\varphi_{1 j s}^{*}}^{\infty}\left[\frac{r_{1 j s}(\varphi)}{w_{1} X_{1 s}}-\frac{\sigma_{s} f_{1 j s}}{X_{1 s}}\right] \frac{g_{1 s}(\varphi)}{\delta_{1 s}} d \varphi & =\frac{\sigma_{s}}{X_{1 s}} F_{1 s} \\
\sum_{j=1,2} \int_{\varphi_{1 j s}^{*}}^{\infty}\left[v_{1 j s}(\varphi)-\frac{\sigma_{s} f_{1 j s}}{X_{1 s}} \frac{g_{1 s}(\varphi)}{\delta_{1 s}}\right] d \varphi & =\frac{\sigma_{s}}{X_{1 s}} F_{1 s} .
\end{array}
$$

Next taking the derivative of both sides with respect to $\varphi_{12 s}^{*}$ and using (A.10), we obtain

$$
\begin{aligned}
0 & =\sum_{j=1,2}\left[\int_{\varphi_{1 j s}^{*}}^{\infty} \frac{d v_{1 j s}(\varphi)}{d \varphi_{12 s}^{*}} d \varphi-\frac{d \varphi_{1 j s}^{*}}{d \varphi_{12 s}^{*}}\left(v_{1 j s}\left(\varphi_{1 j s}^{*}\right)-\frac{\sigma_{s} f_{1 j s} g_{1 s}\left(\varphi_{1 j s}^{*}\right)}{X_{1 s} \delta_{1 s}}\right)\right] \\
& =\sum_{j=1,2} \int_{\varphi_{1 j s}^{*}}^{\infty} \frac{d v_{1 j s}(\varphi)}{d \varphi_{12 s}^{*}} d \varphi \\
& =\int_{\varphi_{12 s}^{*}}^{\infty} \frac{d v_{12 s}(\varphi)}{d \varphi_{12 s}^{*}} d \varphi+\int_{\varphi_{11 s}^{*}}^{\infty} \frac{d v_{11 s}(\varphi)}{d \varphi_{12 s}^{*}} d \varphi \\
& =\int_{\varphi_{12 s}^{*}}^{\infty} \frac{d\left(v_{11 s}(\varphi)+v_{12 s}(\varphi)\right)}{d \varphi_{12 s}^{*}} d \varphi+\int_{\varphi_{11 s}^{*}}^{\varphi_{12 s}^{*}} \frac{d v_{11 s}(\varphi)}{d \varphi_{12 s}^{*}} d \varphi .
\end{aligned}
$$

In response to a marginal decrease in $\varphi_{12 s}^{*}$, the total increase in revenue share of existing exporters $\int_{\varphi_{12 s}^{*}}^{\infty} d\left(v_{11 s}(\varphi)+v_{12 s}(\varphi)\right) / d \varphi_{12 s}^{*} d \varphi$ is exactly balanced by the total decrease in revenue share of remaining non-exporters firms $-\int_{\varphi_{11 s}^{*}}^{\varphi_{12 s}^{*}} d v_{11 s}(\varphi) / d \varphi_{12 s}^{*} d \varphi$.

As a third step in determining the sign of $d \Phi_{1 s}^{R} / d \varphi_{12 s}^{*}$, we look at the change in industrial productivity associated with new exporters and exiting firms. To make progress, we first note that $v_{1 s}(\varphi)$ is a 
density function:

$$
\begin{aligned}
1 & =\int_{0}^{\infty} v_{1 s}(\varphi) d \varphi \\
& =\int_{\varphi_{12 s}^{*}}^{\infty} v_{12 s}(\varphi) d \varphi+\int_{\varphi_{11 s}^{*}}^{\infty} v_{11 s}(\varphi) d \varphi \\
& =\int_{\varphi_{12 s}^{*}}^{\infty}\left[v_{11 s}(\varphi)+v_{12 s}(\varphi)\right] d \varphi+\int_{\varphi_{11 s}^{*}}^{\varphi_{12 s}^{*}} v_{11 s}(\varphi) d \varphi .
\end{aligned}
$$

Next taking the derivative of both sides with respect to $\varphi_{12 s}^{*}$ using Leibniz's Formula, we obtain

$$
\begin{aligned}
0= & \int_{\varphi_{12 s}^{*}}^{\infty}\left[\frac{d\left(v_{11 s}(\varphi)+v_{12 s}(\varphi)\right)}{d \varphi_{12 s}^{*}}\right] d \varphi-\left[v_{11 s}\left(\varphi_{12 s}^{*}\right)+v_{12 s}\left(\varphi_{12 s}^{*}\right)\right]+v_{11 s}\left(\varphi_{12 s}^{*}\right) \\
& +\int_{\varphi_{11 s}^{*}}^{\varphi_{12 s}^{*}}\left(\frac{d v_{11 s}(\varphi)}{d \varphi_{12 s}^{*}}\right) d \varphi-v_{11 s}\left(\varphi_{11 s}^{*}\right) \frac{d \varphi_{11 s}^{*}}{d \varphi_{12 s}^{*}} \\
= & \int_{\varphi_{12 s}^{*}}^{\infty}\left[\frac{d\left(v_{11 s}(\varphi)+v_{12 s}(\varphi)\right)}{d \varphi_{12 s}^{*}}\right] d \varphi-v_{12 s}\left(\varphi_{12 s}^{*}\right) \\
& +\int_{\varphi_{11 s}^{*}}^{\varphi_{12 s}^{*}}\left(\frac{d v_{11 s}(\varphi)}{d \varphi_{12 s}^{*}}\right) d \varphi-v_{11 s}\left(\varphi_{11 s}^{*}\right) \frac{d \varphi_{11 s}^{*}}{d \varphi_{12 s}^{*}}
\end{aligned}
$$

From (A.13), this leads to

$$
v_{12 s}\left(\varphi_{12 s}^{*}\right)+v_{11 s}\left(\varphi_{11 s}^{*}\right) \frac{d \varphi_{11 s}^{*}}{d \varphi_{12 s}^{*}}=0 .
$$

In response to a marginal decrease in $\varphi_{12 s}^{*}$, the total increase in revenue share of new exporters $v_{12 s}\left(\varphi_{12 s}^{*}\right)$ is exactly balanced by the total decrease in revenue share of exiting firms $-v_{11 s}\left(\varphi_{11 s}^{*}\right) \frac{d \varphi_{11 s}^{*}}{d \varphi_{12 s}^{*}}$. It follows that the net effect of the second and the fourth terms in (A.12) is negative

$$
\begin{aligned}
-\varphi_{12 s}^{*} v_{12 s}\left(\varphi_{12 s}^{*}\right)-\varphi_{11 s}^{*} v_{11 s}\left(\varphi_{11 s}^{*}\right) \frac{d \varphi_{11 s}^{*}}{d \varphi_{12 s}^{*}} & =-\varphi_{12 s}^{*} v_{12 s}\left(\varphi_{12 s}^{*}\right)+\varphi_{11 s}^{*} v_{12 s}\left(\varphi_{12 s}^{*}\right) \\
& =-\left(\varphi_{12 s}^{*}-\varphi_{11 s}^{*}\right) v_{12 s}\left(\varphi_{12 s}^{*}\right)<0 .
\end{aligned}
$$

Because the new exporters enter with higher productivity than the firms that are exiting $\left(\varphi_{12 s}^{*}>\varphi_{11 s}^{*}\right)$, this reallocation of revenue shares from exiting firms to new exporters contributes to raising industrial productivity.

Finally, we are ready to determine the sign of $d \Phi_{1 s}^{R} / d \varphi_{12 s}^{*}$. Since $d\left(v_{11 s}(\varphi)+v_{12 s}(\varphi)\right) / d \varphi_{12 s}^{*}<$ 
0 and $d v_{11 s}(\varphi) / d \varphi_{12 s}^{*}>0$,

$$
\begin{aligned}
\varphi \frac{d\left(v_{11 s}(\varphi)+v_{12 s}(\varphi)\right)}{d \varphi_{12 s}^{*}} & <\varphi_{12 s}^{*} \frac{d\left(v_{11 s}(\varphi)+v_{12 s}(\varphi)\right)}{d \varphi_{12 s}^{*}}<0 \text { for all } \varphi>\varphi_{12 s}^{*} \text { and } \\
0<\varphi \frac{d v_{11 s}(\varphi)}{d \varphi_{12 s}^{*}} & <\varphi_{12 s}^{*} \frac{d v_{11 s}(\varphi)}{d \varphi_{12 s}^{*}} \text { for all } \varphi \in\left(\varphi_{11 s}^{*}, \varphi_{12 s}^{*}\right)
\end{aligned}
$$

It follows that the first term on the right-hand-side in (A.12) satisfies the inequality

$$
\int_{\varphi_{12 s}^{*}}^{\infty} \varphi\left[\frac{d\left(v_{11 s}(\varphi)+v_{12 s}(\varphi)\right)}{d \varphi_{12 s}^{*}}\right] d \varphi<\varphi_{12 s}^{*} \int_{\varphi_{12 s}^{*}}^{\infty} \frac{d\left(v_{11 s}(\varphi)+v_{12 s}(\varphi)\right)}{d \varphi_{12 s}^{*}} d \varphi
$$

and the third term satisfies

$$
\begin{aligned}
\int_{\varphi_{11 s}^{*}}^{\varphi_{12 s}^{*}} \varphi\left(\frac{d v_{11 s}(\varphi)}{d \varphi_{12 s}^{*}}\right) d \varphi & <\varphi_{12 s}^{*} \int_{\varphi_{11 s}^{*}}^{\varphi_{12 s}^{*}} \frac{d v_{11 s}(\varphi)}{d \varphi_{12 s}^{*}} d \varphi \\
& =-\varphi_{12 s}^{*} \int_{\varphi_{12 s}^{*}}^{\infty} \frac{d\left(v_{11 s}(\varphi)+v_{12 s}(\varphi)\right)}{d \varphi_{12 s}^{*}} d \varphi \\
& <-\int_{\varphi_{12 s}^{*}}^{\infty} \varphi\left[\frac{d\left(v_{11 s}(\varphi)+v_{12 s}(\varphi)\right)}{d \varphi_{12 s}^{*}}\right] d \varphi
\end{aligned}
$$

Therefore, the net effect of the first and third terms in (A.12) is negative

$$
\int_{\varphi_{12 s}^{*}}^{\infty} \varphi\left[\frac{d\left(v_{11 s}(\varphi)+v_{12 s}(\varphi)\right)}{d \varphi_{12 s}^{*}}\right] d \varphi+\int_{\varphi_{11 s}^{*}}^{\varphi_{12 s}^{*}} \varphi\left(\frac{d v_{11 s}(\varphi)}{d \varphi_{12 s}^{*}}\right) d \varphi<0 .
$$

In response to a marginal decrease in $\varphi_{12 s}^{*}$, the reallocation of revenue shares from remaining nonexporters to existing exporters contributes to raising industrial productivity because all of the existing exporters have higher productivity than any of the remaining non-exporters. Combining (A.14) and (A.15), we conclude that $d \Phi_{1 s}^{R} / d \varphi_{12 s}^{*}<0$.

(Part 2) The second measure of industrial productivity $\Phi_{1 s}^{L}$ is industrial labor productivity:

$$
\Phi_{1 s}^{L} \equiv \frac{\sum_{j=1,2} R_{1 j s}}{\tilde{P}_{1 s} L_{1 s}} \text { where } \tilde{P}_{1 s}=\int_{\varphi_{11 s}^{*}}^{\infty} p_{11 s}(\varphi) \mu_{1 s}(\varphi) d \varphi
$$


From $w_{1} L_{1 s}=\sum_{j=1,2} R_{1 j s}$ and

$$
\begin{aligned}
\tilde{P}_{1 s} & =\int_{\varphi_{11 s}^{*}}^{\infty}\left(\frac{w_{1}}{\rho_{s} \varphi}\right) \frac{g_{1 s}(\varphi)}{1-G_{1 s}\left(\varphi_{11 s}^{*}\right)} d \varphi \\
& =\frac{w_{1}}{\rho_{s}\left(b_{1 s} / \varphi_{11 s}^{*}\right)^{\theta_{s}}} \int_{\varphi_{11 s}^{*}}^{\infty} \frac{\theta_{s} b_{1 s}^{\theta_{s}}}{\varphi^{\theta_{s}+2}} d \varphi \\
& =\frac{w_{1} \theta_{s} \varphi_{11 s}^{* \theta_{s}}}{\rho_{s}}\left[\frac{-\varphi_{11 s}^{*-\left(\theta_{s}+2\right)+1}}{-\left(\theta_{s}+2\right)+1}\right] \\
& =\frac{w_{1}}{\rho_{s} \varphi_{11 s}^{*}}\left(\frac{\theta_{s}}{\theta_{s}+1}\right)
\end{aligned}
$$

industrial labor productivity becomes

$$
\Phi_{1 s}^{L}=\left(\frac{\theta_{s}+1}{\theta_{s}}\right) \rho_{s} \varphi_{11 s}^{*}
$$

From the free entry condition $\sum_{j=1,2} f_{i j s} \varphi_{i j s}^{*-\theta_{s}}=F_{i s} / \gamma_{i s}, \varphi_{11 s}^{*}$ decreases when $\varphi_{12 s}^{*}$ increases. Therefore, $\Phi_{1 s}^{L}$ decreases when $\varphi_{12 s}^{*}$ increases. Furthermore, a change in variable trade costs only affects industrial productivity $\Phi_{1 s}^{L}$ through its influence on $\varphi_{12 s}^{*}$ since the trade costs $\tau_{i j s}$ and the wage $w_{1}$ do not appear separately in the above expression for $\Phi_{1 s}^{L}$ or the free entry condition.

(Part 3) Another measure of industrial productivity $\Phi_{1 s}^{W}$ is industrial labor productivity calculated using a theoretically consistent "exact" price index:

$$
\Phi_{1 s}^{W} \equiv \frac{\sum_{j=1,2} R_{1 j s}}{P_{1 s} L_{1 s}}
$$

It is easy to calculate how a change in $\varphi_{12 s}^{*}$ affects this measure of industrial productivity. Starting from the cut-off productivity condition $(6)$

$$
\begin{aligned}
\frac{r_{11 s}\left(\varphi_{11 s}^{*}\right)}{\sigma_{s}} & =w_{1} f_{11 s} \\
\frac{p_{11 s}\left(\varphi_{11 s}^{*}\right)^{1-\sigma_{s}} \alpha_{s} w_{1} L_{1}}{P_{1 s}^{1-\sigma_{s}}} & =\sigma_{s} w_{1} f_{11 s} \text { from (4) } \\
\left(\frac{w_{1} \tau_{11 s}}{\rho_{s} \varphi_{11 s}^{*} P_{1 s}}\right)^{1-\sigma_{s}} \alpha_{s} w_{1} L_{1} & =\sigma_{s} w_{1} f_{11 s} \text { from (5) } \\
\left(\frac{w_{1}}{P_{1 s}}\right)^{1-\sigma_{s}} & =\frac{\sigma_{s} f_{11 s}}{\alpha_{s} L_{1}}\left(\rho_{s} \varphi_{11 s}^{*}\right)^{1-\sigma_{s}} \\
\frac{w_{1}}{P_{1 s}} & =\left(\frac{\sigma_{s} f_{11 s}}{\alpha_{s} L_{1}}\right)^{1 /\left(1-\sigma_{s}\right)} \rho_{s} \varphi_{11 s}^{*}
\end{aligned}
$$


and then using $w_{1} L_{1 s}=\sum_{j=1,2} R_{1 j s}$, we obtain

$$
\Phi_{1 s}^{W} \equiv \frac{\sum_{j=1,2} R_{1 j s}}{P_{1 s} L_{1 s}}=\frac{w_{1}}{P_{1 s}}=\left(\frac{\alpha_{s} L_{1}}{\sigma_{s} f_{11 s}}\right)^{1 /\left(\sigma_{s}-1\right)} \rho_{s} \varphi_{11 s}^{*} .
$$

From the free entry condition $\sum_{j=1,2} f_{i j s} \varphi_{i j s}^{*-\theta_{s}}=F_{i s} / \gamma_{i s}, \varphi_{11 s}^{*}$ decreases when $\varphi_{12 s}^{*}$ increases. Therefore, $\Phi_{1 s}^{W}$ decreases when $\varphi_{12 s}^{*}$ increases. Furthermore, a change in variable trade costs only affects $\Phi_{1 s}^{W}$ through its influence on $\varphi_{12 s}^{*}$ since the trade costs $\tau_{i j s}$ and the wage $w_{1}$ do not appear separately in the above expression for $\Phi_{1 s}^{W}$ or the free entry condition.

Finally, we derive the welfare formula (23) for the representative consumer in country 1 who supplies one unit of labor. Since her income is $w_{1}$, her aggregate consumption over varieties in sector $s$ is

$$
C_{1 s}=\frac{\alpha_{s} w_{1}}{P_{1 s}}
$$

From the utility function (1) and $\Phi_{1 s}^{W}=w_{1} / P_{1 s}$, her utility is written as:

$$
\begin{aligned}
U & =\left(\frac{\alpha_{A} w_{1}}{P_{1 A}}\right)^{\alpha_{A}}\left(\frac{\alpha_{B} w_{1}}{P_{1 B}}\right)^{\alpha_{B}} \\
& =\left(\alpha_{A} \Phi_{1 A}^{W}\right)^{\alpha_{A}}\left(\alpha_{B} \Phi_{1 B}^{W}\right)^{\alpha_{B}} .
\end{aligned}
$$

